\title{
Article \\ A Concerted Action of UBA5 C-Terminal Unstructured Regions Is Important for Transfer of Activated UFM1 to UFC1
}

\author{
Nicole Wesch ${ }^{1}$, Frank Löhr ${ }^{1}\left(\mathbb{D}\right.$, Natalia Rogova ${ }^{1}$, Volker Dötsch ${ }^{1,2, * \mathbb{D}}$ and Vladimir V. Rogov ${ }^{1,2,3, *}$ \\ 1 Institute of Biophysical Chemistry, Center for Biomolecular Magnetic Resonance, Goethe-University \\ Frankfurt, 60438 Frankfurt am Main, Germany; Wesch@bpc.uni-frankfurt.de (N.W.); \\ Murph@bpc.uni-frankfurt.de (F.L.); Rogova@bpc.uni-frankfurt.de (N.R.) \\ 2 Structural Genomics Consortium, Buchmann Institute for Life Sciences, Goethe-University Frankfurt, \\ 60438 Frankfurt am Main, Germany \\ 3 Institute of Pharmaceutical Chemistry, Goethe-University Frankfurt, 60438 Frankfurt am Main, Germany \\ * Correspondence: vdoetsch@em.uni-frankfurt.de (V.D.); rogov@pharmchem.uni-frankfurt.de (V.V.R.)
}

check for

updates

Citation: Wesch, N.; Löhr, F.; Rogova,

N.; Dötsch, V.; Rogov, V.V. A

Concerted Action of UBA5

C-Terminal Unstructured Regions Is Important for Transfer of Activated UFM1 to UFC1. Int. J. Mol. Sci. 2021, 22, 7390. https://doi.org/10.3390/ ijms22147390

Academic Editors: Istvan Simon and Csaba Magyar

Received: 17 June 2021

Accepted: 6 July 2021

Published: 9 July 2021

Publisher's Note: MDPI stays neutral with regard to jurisdictional claims in published maps and institutional affiliations.

Copyright: (c) 2021 by the authors. Licensee MDPI, Basel, Switzerland. This article is an open access article distributed under the terms and conditions of the Creative Commons Attribution (CC BY) license (https:// creativecommons.org/licenses/by/ $4.0 /)$.
Abstract: Ubiquitin fold modifier 1 (UFM1) is a member of the ubiquitin-like protein family. UFM1 undergoes a cascade of enzymatic reactions including activation by UBA5 (E1), transfer to UFC1 (E2) and selective conjugation to a number of target proteins via UFL1 (E3) enzymes. Despite the importance of ufmylation in a variety of cellular processes and its role in the pathogenicity of many human diseases, the molecular mechanisms of the ufmylation cascade remains unclear. In this study we focused on the biophysical and biochemical characterization of the interaction between UBA5 and UFC1. We explored the hypothesis that the unstructured C-terminal region of UBA5 serves as a regulatory region, controlling cellular localization of the elements of the ufmylation cascade and effective interaction between them. We found that the last 20 residues in UBA5 are pivotal for binding to UFC1 and can accelerate the transfer of UFM1 to UFC1. We solved the structure of a complex of UFC1 and a peptide spanning the last 20 residues of UBA5 by NMR spectroscopy. This structure in combination with additional NMR titration and isothermal titration calorimetry experiments revealed the mechanism of interaction and confirmed the importance of the C-terminal unstructured region in UBA5 for the ufmylation cascade.

Keywords: UFM1; UBA5; UFC1; protein-protein interactions; NMR; complex structure

\section{Introduction}

UFM1 is a small ubiquitin-like (UBL) protein spanning 85 residues. Like other UBLs, it has a low sequence identity to ubiquitin, but shares its specific ( $\beta$-grasp) fold [1,2]. Unlike other UBLs (except for SUMO), UFM1 has a single C-terminal glycine residue, by which UFM1 gets attached to target proteins using an E1-E2-E3 enzymatic cascade [1,3,4]. Initially, the UFM1 precursor protein gets processed by the two specific proteases UfSP1 and UfSP2 to expose the C-terminal glycine residue [5-7]. Processed UFM1 gets activated by UBA5 (E1), a member of the ubiquitin-activating protein family [8-10], from which activated UFM1 is transferred to the catalytic cysteine 116 of UFC1 (E2) [1,8,11]. The last step is the transfer of UFM1 to the target proteins mediated by the specific UFM1 ligase 1 (UFL1), showing no typical E3 ligases domain organization [1,12]. The mechanism of this step is largely unknown and other proteins could be required for UFL1 ligase activity as well [13-16].

The first identified target of UFM1 was Ufm1-binding protein 1 (UFBP1, also known as DDRGK1 or C20orf116) [12]. Since then, discovery of new targets for UFM1 and the characterization of functional consequences of their ufmylation has constantly increased. Recently, new ufmylation targets involved in cancer progression [16,17], DNA damage response [18,19], translation machinery [20] and ribosome functioning [13,14] have been 
identified. Taking in account the broad range of biological pathways affected by ufmylation, it is not surprising that impaired ufmylation can be connected to many human diseases [16,21-24] and seems to be essential for embryonic development [25-27].

The exact mechanism of ufmylation and the full range of physiological consequences are not well investigated yet. The key elements of the ufmylation cascade (UBA5, UFC1, UFL1) show significant evolutionary differences to the well characterized enzymatic UBL cascades (e.g., ubiquitin or NEDD8) resulting in a number of structural and functional deviations from the canonical E1-E2-E3 pathways [3,4,28]. In contrast to other E1 family members, UBA5 does not display the characteristic domain architecture [28]. This 404residue protein possesses a single well-folded adenylation domain (residues 57-329), comprising the active site Cys250 and provides a platform for ATP binding and UFM1 activation [8,29]. Two UBA5 regions-the $\mathrm{N}$-terminal (1-56) and the C-terminal (334-404) segments-appear to be important regulatory elements for the function of UBA5 and in the ufmylation cascade. The N-terminal segment $1-56$ (absent in one of the two existing UBA5 splice isoforms) significantly enhances ATP binding and therefore increases efficiency and velocity of UFM1 activation. Additionally, the N-terminal extension accelerates UFM1 transfer to UFC1 from the UBA5 UFM1 conjugate in presence of ATP [30].

The UBA5 C-terminal part (Figure 1A) plays a complex regulatory role, consisting of a few conserved regions that mediate interaction of UBA5 with other key players in the ufmylation cascade [31]. The first sequence is a conserved region (R1, residues 334-348), interacting with UFM1 [10,29-32] and also with LC3/GABARAP proteins [31,33]. This region (called LIR/UFIM by its dual nature) is important for the initial binding of UFM1 to UBA5 [10,29,31,32] and for the following UFM1 activation in a trans-fashion [29]. Trans-activation means that UBA5 forms an active homodimer, like other non-canonical E1 enzymes, and UFM1 bound to the LIR/UFIM segment of one monomer exposes its C-terminal Gly83 residue to the catalytic Cys250 of the other monomer [29]. GABARAP (and to a lesser extend LC3) proteins interact with the same UBA5 region and inhibit UFM1 binding to UBA5, thus modulating the conjugation of UFM1 to UBA5 and to UFC1 in vitro [31]. No evidence for the activation of LC3/GABARAP proteins by UBA5 was found so far. However, we showed previously that interaction between GABARAP proteins and UBA5 facilitates membrane localization of the latter [33].

The second region (R2, residues 364-372) is significantly less conserved among different species than the first region, with only Gly367 being evolutionary invariant. The role of this region is not understood, and no interacting proteins could be identified so far. However, a A371T mutation in the human protein located in this region decreases the ability of UBA5 to activate UFM1, to transfer the activated UFM1 to UFC1 and to mediate UFBP1 UFM1 formation [25,34].

Another conserved region in UBA5 is located at it very C-terminus (R3, residues 393-404) and is predicted to have a helical conformation. Initially, it was postulated by analogy with canonical E1 enzymes that the UBA5 C-terminal part possesses an ubiquitinfold domain, mediating UBA5 interaction with UFC1 $[8,11]$. Later it was shown that a short UBA5 peptide (residues 381-404) is solely responsible for this interaction [32]. UFC1, the only known E2 enzyme for UFM1, was characterized structurally $[11,35]$ a few years after discovery of the UFM1 cascade [1]. The common architecture of E2 enzymes-four $\alpha$ helices, four $\beta$-strands and one $3_{10}$-helix (reviewed in [28]) - is conserved for the UFC1 core (25-157). Lack of C-terminal $\alpha$-helices and conserved motifs as well as the presence of an $\mathrm{N}$-terminal $\alpha$-helix, which stabilizes the UFC1 structure [11] result in structural differences, which classify UFC1 as a non-canonical E2 enzyme. Computational modeling (based on the existing crystal structure of the E1:E2 complex for the NEDD8 cascade) revealed that the second $\alpha$-helix in UFC1 is the most probable site for interaction with UBA5. Indeed, the UFC1 K33A mutation significantly reduces both UBA5 binding and UFM1 transfer from UBA5 to UFC1 [11]. 
A

$\mathrm{N}$-teminal part

C-teminal part

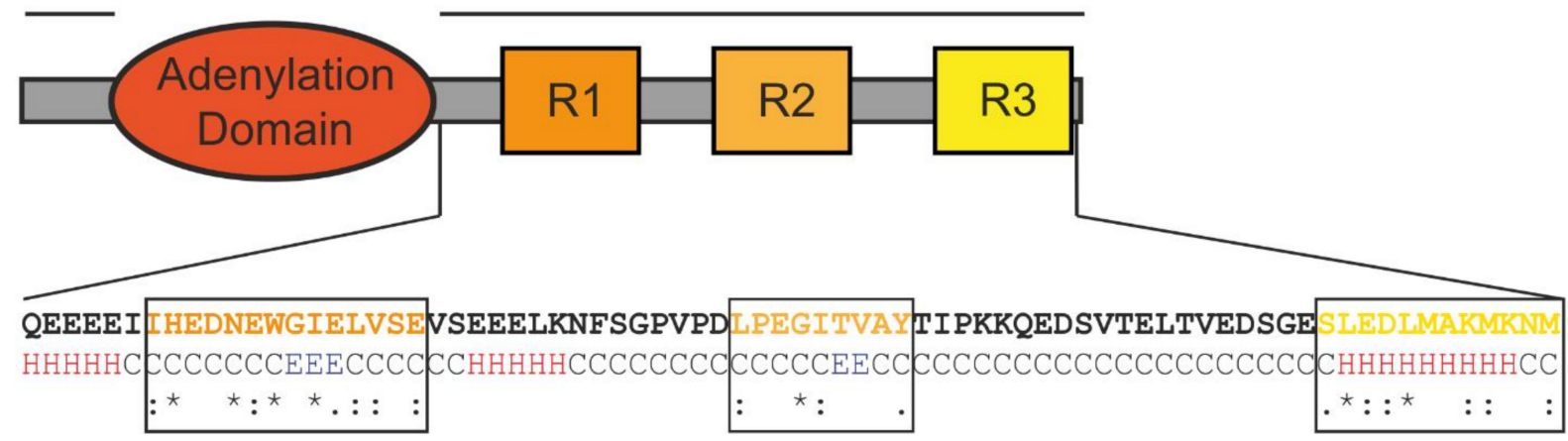

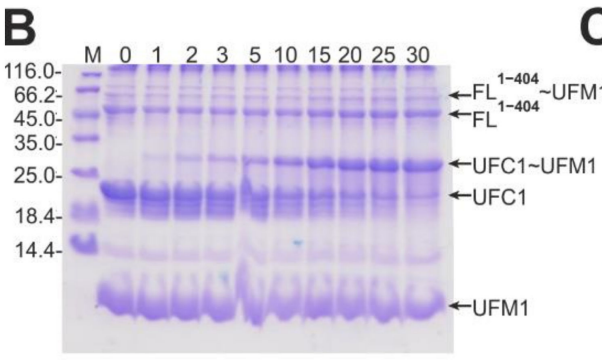

E

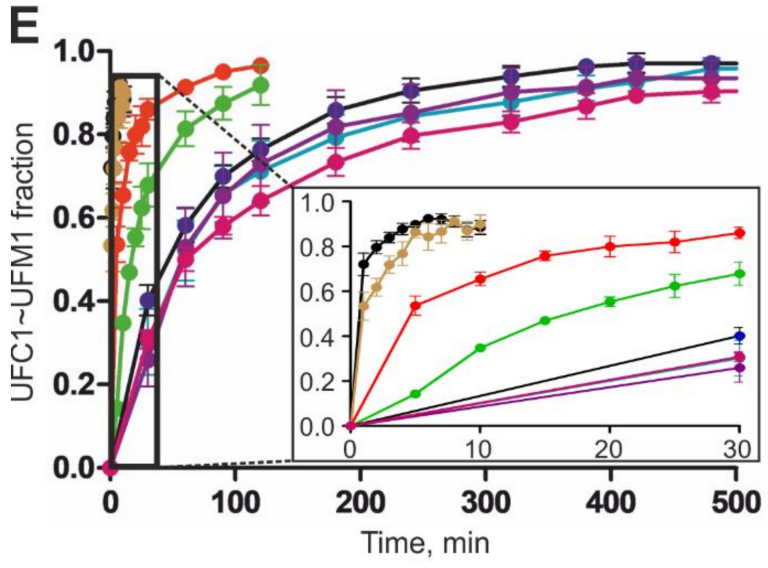

D M 01223551015202530

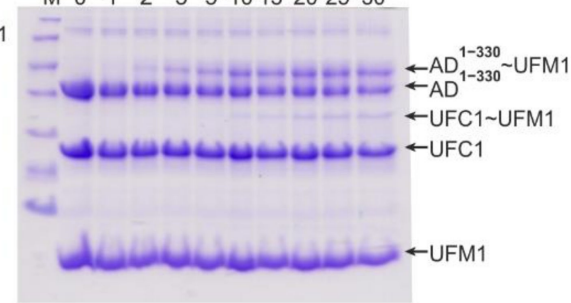

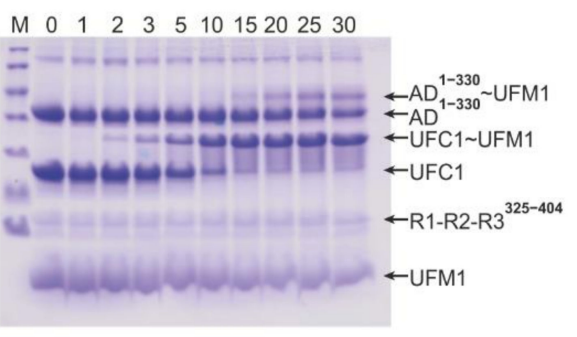

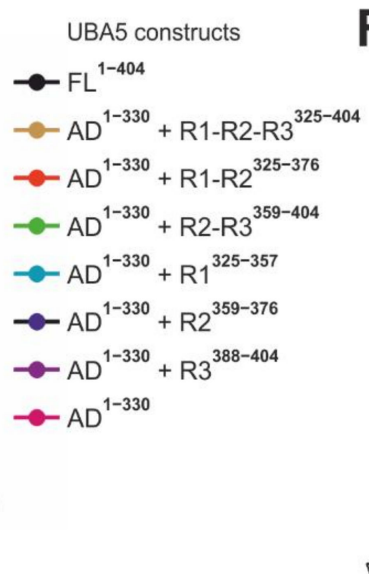

$\mathbf{F}$

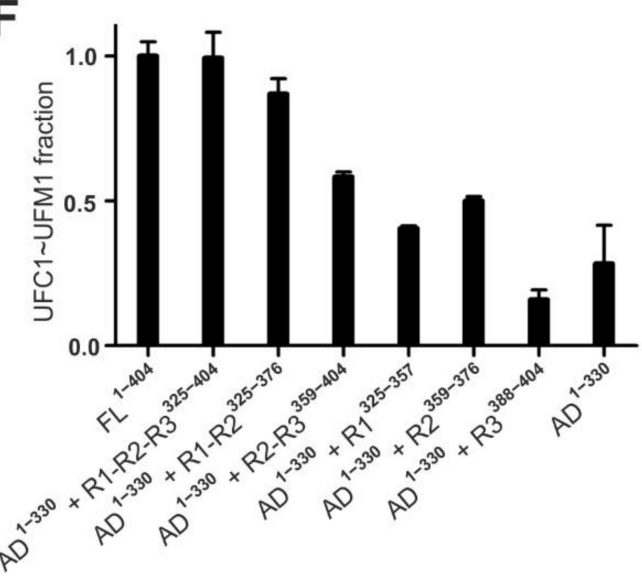

Figure 1. Role of C-terminal UBA5 regions on UFC1 UFM1 conjugation. (A) Overview of UBA5 conserved regions. Structure prediction (JPRED) and residue conservation are indicated below the C-terminal sequence (* indicates fully conserved residues; : indicates residues of high similarity; . indicates residues of low similarity). The different UBA5 C-terminal conserved regions are highlighted. (B-D) Gel electrophoresis of ufmylation assays including UBA5 FL ${ }^{1-404}$ (B), $\mathrm{AD}^{1-330}(\mathbf{C})$ and a mixture of UBA5 $\mathrm{AD}^{1-330}$ and R1-R2-R3 $325-404$ (D) as E1 enzymes. Ufmylation was tracked over $30 \mathrm{~min}$. Corresponding protein bands are labeled on the right side. (E) Ufmylation assays tracked over time with different UBA5 constructs indicated on the right side. The time points of 0-30 min are magnified. All assays were done as triplicates. Evaluation of UFC1 UFM1 conjugate was done via Western blotting. (F) Ufmylation assays quantified after 30 min reaction time. The fractions of the UFC1 UFM1 species are presented as bar diagram for each reaction mixture. For quantification of conjugated and unconjugated UFC1 coloc2 software implemented in Image J was used.

Despite these previous investigations, structural aspects and molecular mechanisms of the interaction between UBA5 and UFC1 are still largely unknown. Additionally, it is not clear, if other factors (e.g., UFM1 conjugated or bound to UBA5, or UFC1) could affect this interaction. In order to fill this gap, we systematically analyzed by isothermal titration calorimetry and NMR spectroscopy the interactions between different UBA5 fragments and UFC1, UFM1 and LC3/GABARAP proteins. Using this knowledge, we solved the solution structure of UFC1 in complex with an optimized C-terminal fragment of UBA5. 
Finally, our biochemical experiments showed the importance of the UBA5:UFC1 interaction for effective ufmylation.

\section{Results}

\subsection{The UBA5 C-Terminal Part Is a Regulatory Platform for the Ufmylation Cascade}

In order to understand the importance of the whole UBA5 C-terminal part and the roles of its individual conserved regions, we cloned and expressed a set of constructs containing the whole C-terminus, individual conserved regions and their combinations (Table 1) and investigated their interaction with the key elements of the ufmylation cascade.

Table 1. A list of DNA constructs used in this study.

\begin{tabular}{|c|c|c|c|}
\hline DNA Construct & Expressed Protein/Peptide & Short Description & References \\
\hline pET39_Ub19_UBA5 $5^{1-404}$ & $\mathrm{FL}^{1-404}$ & Full length UBA5, residues 1-404 & [31] \\
\hline pET39_Ub19_UBA5 ${ }^{325-404}$ & R1-R2-R3 ${ }^{325-404}$ & UBA5 C-terminal part, residues 325-404 & [31] \\
\hline pET39_Ub19_UFM1 & UFM1 & Full length UFM1, residues $2-83$ & [31] \\
\hline pETm60_Ub3_LC3A & LC3A & LC3A, residues $4-120$ & [36] \\
\hline pETm60_Ub3_LC3B & LC3B & LC3B, residues 5-120 & [36] \\
\hline pET39_Ub19_LC3C & LC3C & LC3C, residues 5-126 & [36] \\
\hline pET39_Ub19_GABARAP & GABARAP & GABARAP, residues 3-116 & [36] \\
\hline pETm60_Ub3_GABARAPL1 & GABARAPL1 & GABARAPL1, residues 2-116 & [36] \\
\hline pET39_Üb19_GABARAPL2 & GABARAPL2 & GABARAPL2, residues 3-116 & [36] \\
\hline pETm60_Ub & Ubiquitin & Ubiquitin, residues $1-76$ & [37] \\
\hline pET39_Ub19_UFC1 & UFC1 & Full length UFC1, residues 1-167 & This work \\
\hline pET39_Ub19_UBA5 $5^{1-330}$ & $\mathrm{AD}^{1-330}$ & UBA5 adenylation domain, residues $1-330$ & This work \\
\hline pET39_Ub19_UBA5 $5^{325-376}$ & $\mathrm{R} 1-\mathrm{R} 2^{325-376}$ & $\begin{array}{c}\text { UBA5 C-terminal regions } \mathrm{R} 1 \text { and } \mathrm{R} 2 \text {, } \\
\text { residues } 325-376\end{array}$ & This work \\
\hline pET39_Ub19_UBA5 $5^{359-404}$ & $\mathrm{R} 2-\mathrm{R} 3^{359-404}$ & $\begin{array}{l}\text { UBA5 C-terminal regions R2 and R3, } \\
\text { residues 359-404 }\end{array}$ & This work \\
\hline pET39_Ub19_UBA5 $5^{325-357}$ & $\mathrm{R} 1^{325-357}$ & UBA5 C-terminal region $\mathrm{R} 1$, residues $325-357$ & This work \\
\hline pET39_Ub19_UBA5 $5^{359-376}$ & $\mathrm{R}^{359-376}$ & UBA5 C-terminal region $\mathrm{R} 2$, residues 359-376 & This work \\
\hline pET39_Ub19_UBA5 ${ }^{388-404}$ & $\mathrm{R} 3^{388-404}$ & UBA5 C-terminal region R3, residues 388-404 & This work \\
\hline pET39_Ub19_UBA5 $5^{381-404 W}$ & $\mathrm{R} 3^{381-404 \mathrm{~W}}$ & $\begin{array}{c}\text { Optimized R3, residues 381-404 with } \\
\text { C-terminal W }\end{array}$ & This work \\
\hline pET39_Ub19_UBA5 ${ }^{325-404}$ A371T & R1-R2-R3 ${ }^{325-404}$ A371T & $\begin{array}{l}\text { UBA5 C-terminal part with A371T mutant } \\
\text { (res. 325-404) }\end{array}$ & This work \\
\hline pET39_Ub19_UBA5 ${ }^{325-404}$ A371E & R1-R2-R3 ${ }^{325-404}$ A371E & $\begin{array}{l}\text { UBA5 C-terminal part with A371E mutant } \\
\text { (res. 325-404) }\end{array}$ & This work \\
\hline pET39_Ub19_UBA5 $5^{1-380}$ & $\Delta \mathrm{R} 3^{1-380}$ & UBA5 with deleted R3 region, residues $1-380$ & This work \\
\hline pNiC-CTH0_UBA5 ${ }^{1-404}$ C250K & $\mathrm{FL}^{1-404} \mathrm{C} 250 \mathrm{~K}$ & $\begin{array}{l}\text { Full length UBA5 (res. 1-404) with } \\
\text { C250K mutant }\end{array}$ & This work \\
\hline pET39_Ub19_UBA5 $5^{1-330}$ C250K ${ }^{0}$ & $\mathrm{AD}^{1-330} \mathrm{C} 250 \mathrm{~K}$ & UBA5 adenylation domain with C250K mutant & This work \\
\hline pNiC-CTH0_UFC1 & UFC1_His6 & $\begin{array}{l}\text { Full length UFC1 with C-terminal } \\
\text { hexahistidine-tag }\end{array}$ & This work \\
\hline
\end{tabular}

First, we analyzed the effect of the UBA5 C-terminus on UFM1 transfer to UFC1 with an in vitro thioester formation assay (Figure 1B-E). Using UBA5 full length protein as E1 enzyme, we observed fast formation of a UFC1 UFM1 conjugate ( $90 \%$ UFC1 was conjugated to UFM1 within $30 \mathrm{~min}$, Figure 1B). When we used C-terminally truncated UBA5 (only the adenylation domain - $\mathrm{AD}$, residues 1-330) as E1 enzyme, formation of a UFC1 UFM1 conjugate was significantly reduced (less than 5\% UFC1 UFM1 conjugation was reached within $30 \mathrm{~min} ; 7 \mathrm{~h}$ were needed to reach $80 \%$ UFC1 UFM1 conjugation, Figure 1C). However, transfer of UFM1 to UFC1 was rescued when we used an equimolar mixture of the UBA5 AD and the UBA5 C-terminal part as E1 enzyme. In this case, the ure 1D). These results indicate a crucial role of the UBA5 C-terminal part in the ufmylation cascade.

The most important regions in the UBA5 C-terminal parts-R1 (containing the LIR/UFIM sequence) and R3 (containing the UFC1 binding sequence)—seem to have a cumulative effect on the ability of UBA5 to transfer activated UFM1 on UFC1. Addition to the reaction 
mixture (UBA5 $\mathrm{AD}^{1-330}$, UFC1, UFM1, ATP $/ \mathrm{Mg}^{+}$) of UBA5 peptides lacking either the R1 or R3 sequences led to a reduced conjugation rate (Figure 1E and Supplementary Figure S1A). The results also indicate that the LIR/UFIM sequence is more important for the ufmylation cascade than the R3 site and that the conserved region R2 could also play an additive role in this process: the level of UFC1 UFM1 conjugates reached in reactions with $\mathrm{AD}^{1-330} / \mathrm{R} 1-\mathrm{R} 2^{325-376}$ a higher level than when the $\mathrm{R} 1^{325-357}$ peptide was added alone. Similarly, the addition of the isolated $\mathrm{R} 2^{359-376}$ and $\mathrm{R} 3^{381-404 \mathrm{~W}}$ peptides had virtually no effect on the ufmylation reaction (Figure 1E and Supplementary Figure S1B).

UBA5 mutations within the R2 sequence (A371T and it phosphomimicking variant A371E) did not affect significantly the formation of the UFC1 UFM1 conjugate (Supplementary Figure S1C), indicating that the mutation becomes important for downstream events in the ufmylation cascade - potentially during binding of UBA5 to the membrane-associated E3 ligase (UFL1), to targets (UFBP1 [12], ASC1 [16], p53 [17], etc.) or important for other regulatory events. However, in another assay, using a mixture of wild type and mutated full length UBA5 proteins, we observed a small but reproducible reduction of UFC1 UFM1 conjugation (Supplementary Figure S1D).

Taken together we were able to restore the UFM1 transfer to UFC1 with separated AD and C-terminal peptides. With the single $\mathrm{AD}$ and only one of the regions the reaction took $7 \mathrm{~h}$. The reaction rate increased by addition of peptides containing two regions and was similar to the full length UBA5 containing the complete C-terminal part.

\subsection{Interactions between Different UBA5 C-Terminal Regions and UFC1, UFM1 and LC3/GABRAP Proteins}

To understand how the UBA5 C-terminus participates in the ufmylation cascade, we performed isothermal titration calorimetry (ITC) experiments, in which we titrated UBA5 C-terminal peptides (see Table 1) to the UBA5 AD, UFC1, UFM1 and representative LC3/GABARAP proteins (Figure 2A, Supplementary Figure S2A-D and Table 2). The ITC experiments revealed that the entire UBA5 C-terminus (R1-R2-R3 ${ }^{325-404}$ ) does not interact with the UBA5 AD, forming an independent UBA5 domain (Supplementary Figure S2A). The affinity of UFM1 to the R1-containing peptides (R1-R2-R3 $325-404$ and R1-R2 $325-376$, Supplementary Figure S2B and Table 2) does not change significantly compared to the affinity of the isolated $\mathrm{R} 1^{325-357}$ peptide [31], indicating that this interaction is completely located within the LIR/UFIM containing region.

In contrast, LC3/GABARAP proteins showed a 10-fold higher affinity to the R1-R2$\mathrm{R} 3^{325-404}$ and R1-R2 ${ }^{325-376}$ peptides compared to the isolated LIR/UFIM motif (R1 ${ }^{337-348}$ ) characterized in $[31,33]$. The $K_{D}$ values for interactions between R1-R2-R3 $3^{325-404}$ and GABARAPL2 $(0.17 \mu \mathrm{M})$ or LC3B $(3.7 \mu \mathrm{M})$ indicate the same subfamily-specific preferences that were reported previously (Supplementary Figure S2C,D).

The affinity of the interaction between UBA 5 and UFC 1 has not been characterized previously. In ITC experiments, the shortest UBA5 peptide spanning the R3 sequence (R3 $3^{388-404}$ ) bound to UFC1 with a $\mathrm{K}_{\mathrm{D}}$ of $>11 \mu \mathrm{M}$. The affinity increased 3-fold for R2$\mathrm{R}^{359-404}$ and R1-R2-R3 ${ }^{325-404}$ peptides $\left(\mathrm{K}_{\mathrm{D}}\right.$ of 2.7 and $2.4 \mu \mathrm{M}$, respectively; Figure $2 \mathrm{~A}$ and Table 2).

UFM1 and LC3/GABARAP proteins did not show interaction with the R2 region. However, R1-R2-R3 ${ }^{325-404}$ peptides containing A371T and A371E mutations showed some increase in affinity to LC3B and GABARAPL2 proteins but not to UFM1 and UFC1 (Supplementary Figure S2E,F, Table 2).

To understand the role of the UBA5 C-terminal region in coordination of the binding events reported above on the molecular level, we performed NMR titration experiments. In those experiments, we titrated non-labeled UFC1 and GABARAPL2 proteins to a ${ }^{15} \mathrm{~N}$ labeled R1-R2-R3 $3^{325-404}$ peptide. The NMR experiments revealed that the interaction between UFC1 and UBA5 is mediated mostly by the UBA5 residues 386-404. These residues (in contrast to the vast majority of the R1-R2-R3 $3^{325-404}$ resonances, which are not affected by addition of UFC1) showed a slow-to-intermediate exchange mode. The amide backbone resonances of these residues disappeared with small chemical shift perturbation 
(CSP) at the earlier stages of titrations and did not appear again up to an 8-fold molar excess of UFC1 (Figure 2B, the full size spectra are presented in Supplementary Figure S3D). UBA5 residues 383-386, 400 and 403 appeared to be in intermediate exchange mode (their amide backbone resonances displayed CSP with intensity change, however, they became visible at the latest titration steps). It seems, that these UBA5 residues form additional interactions with UFC1. Interestingly, a subset of the residues within the R2 region (V370, A371, Y372 and T373) displayed moderate CSPs, however, below standard deviation level (Figure 2C), possibly indicating an influence of the UBA5 A371T mutation on the recognition of UFC1.

The GABARAPL2 titration to the R1-R2-R3 ${ }^{325-404}$ peptide revealed a complex behavior of interactions between these two polypeptides (Supplementary Figure S3A,B). At the earlier stages of titrations (until a molar ratio of 1:1) the R1-R2-R3 $3^{325-404}$ resonances showed significant CSPs (in slow-to-intermediate exchange mode), mostly within the LIR/UFIM region (residues D338-V349). Moderate CSPs (with magnitudes above one standard deviation level) can also be observed in sequences adjacent to the R1 peptide: I335 N-terminally, and E352-S358 C-terminally. However, increased concentrations of GABARAPL2 induce further CSPs over the entire R1-R2-R3 ${ }^{325-404}$ peptide sequence, including residues in R2 (A371-I374) and R3 (V382-G391, L394, D396, M398) regions. For the resonances within the R1 and adjacent sequences, the direction of the CSPs changed (Supplementary Figure S3A), while residues in $\mathrm{R} 2 / \mathrm{R} 3$ regions approach the slow-exchange regime with increased CSP values. These observations indicate, that GABARAPL2 binds first to the LIR/UFIM region, and after saturation of this binding site, GABARAPL2 interacts with additional sites within the UBA5 C-terminus. According to this model, high concentration of GABARAPL2 could efficiently prohibit the UFC1 UFM1 conjugation, which was observed in ufmylation assays (Supplementary Figure S3C).

Table 2. Thermodynamic parameters of the interactions between UBA5 C-terminal regions and UBA5-interacting proteins.

\begin{tabular}{|c|c|c|c|c|c|c|c|c|}
\hline Proteins & UBA5 Regions & $\begin{array}{c}\Delta \mathrm{H} \\
\left(\mathrm{kcal} \mathrm{mol}^{-1}\right)\end{array}$ & $\begin{array}{c}\Delta S \\
\left(\mathrm{cal} \mathrm{mol}^{-1} \mathrm{~K}^{-1}\right)\end{array}$ & $\begin{array}{c}-\mathrm{T}^{*} \Delta \mathrm{S} \\
\left(\mathrm{kcal} \mathrm{mol}^{-1}\right)\end{array}$ & $\begin{array}{c}\Delta \mathrm{G} \\
\left(\mathrm{kcal} \mathrm{mol}^{-1}\right)\end{array}$ & $\begin{array}{c}\mathrm{K}_{\mathrm{A}}{ }^{*} 10^{-6} \\
\left(\mathrm{M}^{-1}\right)\end{array}$ & $\begin{array}{c}\mathrm{K}_{\mathrm{D}} \\
(\mu \mathrm{M})\end{array}$ & $\mathbf{N}$ \\
\hline \multirow[t]{5}{*}{ UFM1 } & R1-R2-R3 ${ }^{325-404}$ & $-5.83 \pm 0.20 *$ & 4.41 & -1.31 & -7.15 & $0.17 \pm 0.02$ & 5.8 & $1.04 \pm 0.03$ \\
\hline & R1-R2 $325-376$ & $-5.61 \pm 0.21$ & 4.99 & -1.49 & -7.10 & $0.16 \pm 0.01$ & 6.2 & $0.96 \pm 0.03$ \\
\hline & $R 2^{359-376}$ & ND & & & & ND & $>100 * *$ & ND \\
\hline & R1-R2-R3 ${ }^{325-404}$ A371T & $-10.99 \pm 0.25$ & -13.3 & 3.96 & -7.02 & $0.14 \pm 0.01$ & 7.1 & $1.12 \pm 0.02$ \\
\hline & R1-R2-R3 ${ }^{325-404}$ A371E & $-11.42 \pm 0.42$ & -15.3 & 4.56 & -6.86 & $0.11 \pm 0.01$ & 9.2 & $1.01 \pm 0.01$ \\
\hline \multirow[t]{8}{*}{ UFC1 } & R1-R2-R33 ${ }^{325-404}$ & $-7.04 \pm 0.07$ & 2.09 & -0.62 & -7.66 & $0.41 \pm 0.02$ & 2.4 & $1.03 \pm 0.01$ \\
\hline & R2-R3 $359-404$ & $-8.08 \pm 0.10$ & 1.59 & -0.47 & -7.60 & $0.37 \pm 0.01$ & 2.7 & $0.97 \pm 0.01$ \\
\hline & $\mathrm{R} 3^{388-404}$ & $-4.99 \pm 0.22$ & 6.91 & -2.06 & -7.05 & $0.03 \pm 0.003$ & 10 & $0.95 \pm 0.03$ \\
\hline & $\mathrm{R} 2^{359-376}$ & ND & & & & ND & $>50 * *$ & ND \\
\hline & R1-R2-R3 ${ }^{325-404}$ A371T & $-7.88 \pm 0.08$ & -0.19 & 0.06 & -7.82 & $0.54 \pm 0.03$ & 1.8 & $1.03 \pm 0.008$ \\
\hline & R1-R2-R3 ${ }^{325-404}$ A371E & $-7.78 \pm 0.05$ & 0.36 & -0.11 & -7.88 & $0.60 \pm 0.02$ & 1.6 & $1.03 \pm 0.005$ \\
\hline & $\mathrm{FL}^{1-404}$ & $-7.62 \pm 0.01$ & 1.26 & -0.38 & -8.00 & $0.72 \pm 0.04$ & 1.4 & $0.97 \pm 0.009$ \\
\hline & $\mathrm{FL}^{1-404} \mathrm{C} 250 \mathrm{~K} \sim \mathrm{Ufm} 1$ & $-8.21 \pm 0.01$ & -0.34 & 0.10 & -8.10 & $0.87 \pm 0.05$ & 1.2 & $1.03 \pm 0.009$ \\
\hline \multirow[t]{5}{*}{ GABARAPL2 } & R1-R2-R3 $325-404$ & $-8.64 \pm 0.06$ & 2.04 & -0.61 & -9.25 & $5.99 \pm 0.49$ & 0.17 & $0.97 \pm 0.004$ \\
\hline & R1-R2 $325-376$ & $-8.08 \pm 0.05$ & 4.44 & -1.32 & -9.41 & $7.87 \pm 0.74$ & 0.13 & $0.91 \pm 0.003$ \\
\hline & $\mathrm{R} 2^{359-376}$ & ND & & & & ND & $>100 * *$ & ND \\
\hline & R1-R2-R3 ${ }^{325-404}$ A371T & $-7.58 \pm 0.07$ & 7.76 & -2.31 & -9.89 & $17.90 \pm 3.75$ & 0.06 & $0.937 \pm 0.005$ \\
\hline & R1-R2-R3 ${ }^{325-404}$ A371E & $-7.79 \pm 0.05$ & 7.23 & -2.16 & -9.95 & $19.60 \pm 2.57$ & 0.06 & $1.01 \pm 0.003$ \\
\hline \multirow[t]{2}{*}{ GABARAP } & R1-R2-R3 ${ }^{325-404}$ & $-0.93 \pm 0.04$ & 24.2 & -7.22 & -8.15 & $0.96 \pm 0.16$ & 1.1 & $0.99 \pm 0.03$ \\
\hline & R1-R2 $325-376$ & $-1.1 \pm 0.02$ & 23.1 & -6.89 & -7.99 & $0.72 \pm 0.05$ & 1.4 & $0.94 \pm 0.01$ \\
\hline \multirow[t]{5}{*}{ LC3B } & R1-R2-R3 ${ }^{325-404}$ & $-4.47 \pm 0.10$ & 8.86 & -2.64 & -7.33 & $0.24 \pm 0.09$ & 4.2 & $0.92 \pm 0.02$ \\
\hline & R1-R2 $225-376$ & $-4.23 \pm 0.09$ & 10.7 & -3.19 & -7.42 & $0.27 \pm 0.14$ & 3.7 & $0.98 \pm 0.02$ \\
\hline & $\mathrm{R} 2^{359-376}$ & ND & & & & ND & $>100 *$ & ND \\
\hline & R1-R2-R3325-404 A371T & $-3.76 \pm 0.05$ & 14.3 & -4.26 & -8.02 & $0.76 \pm 0.04$ & 1.3 & $0.937 \pm 0.009$ \\
\hline & R1-R2-R3 ${ }^{325-404}$ A371E & $-3.93 \pm 0.05$ & 15.3 & -4.56 & -8.49 & $1.66 \pm 0.12$ & 0.6 & $0.944 \pm 0.009$ \\
\hline \multirow{2}{*}{ LC3A } & R1-R2-R3 ${ }^{325-404}$ & $4.25 \pm 10.5$ & 10.5 & -3.13 & -7.38 & $0.26 \pm 0.03$ & 3.8 & $0.91 \pm 0.04$ \\
\hline & R1-R2 $2^{325-376}$ & $-3.81 \pm 0.18$ & 11.6 & -3.46 & -7.26 & $0.21 \pm 0.02$ & 4.7 & $0.94 \pm 0.03$ \\
\hline UBA5 AD $^{1-330}$ & R1-R2-R3325-404 & ND & & & & ND & - & ND \\
\hline $\mathrm{Ub}$ & R1-R2-R3 ${ }^{325-404}$ & ND & & & & ND & - & ND \\
\hline
\end{tabular}

${ }^{*}$ Here and further the \pm sign corresponds to a fitting error of the individual experiment. ${ }^{* *}$ Estimated value. 
A

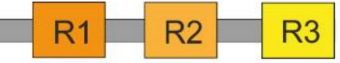

Time [min]

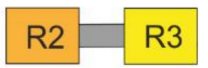

Time [min]
R3
$\mathrm{R} 2$

Time [min]
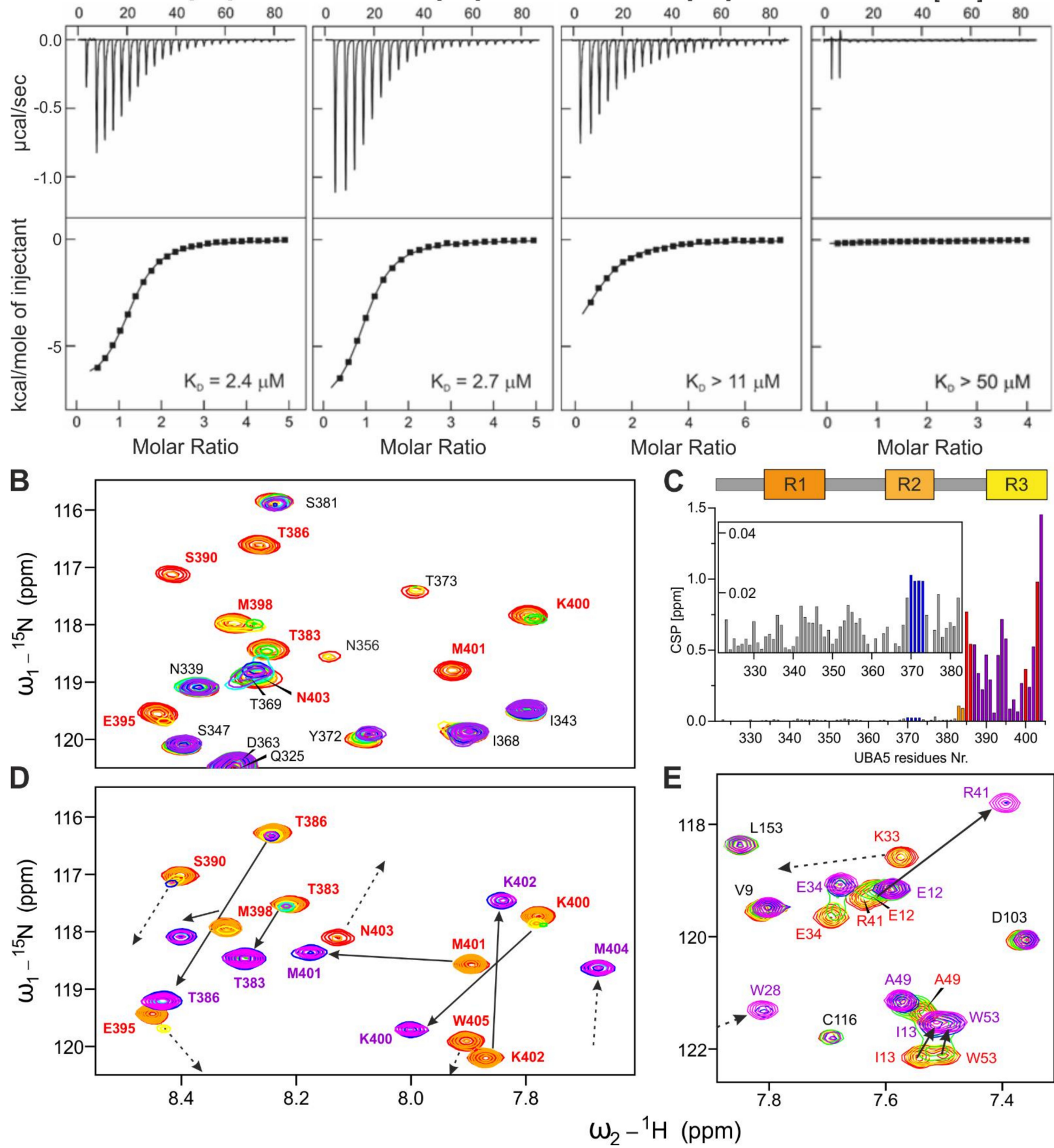

Figure 2. Interaction between UBA5 C-terminal fragments and UFC1 protein. (A) UFC1 binding to different UBA5 Cterminal peptides observed by ITC experiments. The upper graphs display the raw heat data; the lower graphs show the integrated heat per titration steps (black squares) with best-fit curve (line). The used peptides are graphically visualized above the corresponding titration profiles. $K_{D}$ values are indicated. (B) NMR titration of ${ }^{15} \mathrm{~N}-$ labeled R1-R2-R3 ${ }^{325-404}$ peptide with non-labeled UFC1. An overlay of representative areas of the $\left[{ }^{15} \mathrm{~N},{ }^{1} \mathrm{H}\right]$ TROSY-HSQC spectra recorded at $500 \mathrm{MHz}$ are presented. The increasing protein molar ratios are indicated with a rainbow color code from free R1-R2-R3 ${ }^{325-404}$ (red) to 
8 molar excess of UFC1 (purple). (C) Mapping of CSPs induced by UFC1 on the R1-R2-R3 ${ }^{325-404}$ sequence. The CSP values (shown as bars) below standard deviation (SD), between 1xSD and 2xSD, and above 2xSD are labeled grey, yellow and red, respectively. The small box shows magnification of CSP diagram for UBA5 residues 325-382. The disappearing resonances within the core R3 sequence are also shown as purple bars; the CSP for the R2 residues around A371 are marked blue. (D) NMR titration of the ${ }^{13} \mathrm{C},{ }^{15} \mathrm{~N}$-labeled $\mathrm{R} 3{ }^{381-404 \mathrm{~W}}$ peptide with non-labeled UFC1 protein performed at $800 \mathrm{MHz}$. The same spectral areas as in (B) are shown and the same color code is used. (E) NMR titration of ${ }^{15} \mathrm{~N},{ }^{13} \mathrm{C}$-labeled UFC1 with non-labeled R3 ${ }^{381-404 \mathrm{~W}}$ peptide recorded at $950 \mathrm{MHz}$. An overlay of representative areas of the $\left[{ }^{15} \mathrm{~N},{ }^{1} \mathrm{H}\right] \mathrm{TROSY}-\mathrm{HSQC}$ spectra is presented. Titration steps are visualized in a rainbow color code. Most significant CSP are highlighted by arrows. Dashed arrows indicate that the initial or final peak position is outside of the presented area.

We could not observe any interactions between UFM1 and UFC1 proteins (using NMR titration of ${ }^{15} \mathrm{~N}$-labeled UFC1 with non-labeled UFM1 up to 1:2 molar ratio). Additionally, binding of UFC1 to the R3 region within the UBA5 C-terminus ${ }^{325-404}$ did not initiate UFC1:UFM1 interactions as displayed by NMR experiments of ${ }^{15} \mathrm{~N}$-labeled UFC1 in complex with the R1-R2-R3 ${ }^{325-404}$ peptide titrated with non-labeled UFM1 until a 1:4 molar ratio. Furthermore, no interaction of ubiquitin to the UBA5 C-terminal region was observed, suggesting that the UBA5 C-terminus is specific for UFM1.

Taken together, we identified a UFC1-interacting region within the UBA5 C-terminus using ITC and NMR experiments. The region is slightly longer than the conserved R3 sequence which was detected previously and shows a micromolar affinity to UFC1. While UFM1 seems to bind only to the LIR/UFIM region of UBA5, LC3/GABARAP proteins interact with additional residues outside of the of the R1 sequence. LC3 and GABARAP subfamily proteins showed a 10-fold higher affinity to the complete UBA5 C-terminus compared to the isolated R1 peptide. Additionally, UFC1 showed interaction outside of the $\mathrm{R} 3$ region, binding residues within the R2 region. NMR titrations revealed that UFC1 and GABARAPL2 have a more complex binding mechanism to the UBA5 C-terminus, involving some residues in the $\mathrm{R} 2$ region. However, no direct interactions of all tested proteins to the isolated R2 peptide were observed.

\subsection{Structure of UFC1 in Complex with the UBA5 R3 Peptide}

To understand the interaction between UFC1 and UBA5 on a molecular level, we solved the NMR solution structure of UFC1 in complex with the UBA5 R $381-404 \mathrm{~W}$ peptide. Based on the results of our ITC and NMR experiments, we optimized the R3 peptide sequence including residues 381-404 of UBA5 and an additional C-terminal tryptophan residue (at position 405), providing a possibility to calculate the peptide concentration by UV spectroscopy. The $\mathrm{R}^{381-404 \mathrm{~W}}$ peptide displayed the expected ability to form a stable complex with UFC1. In contrast to the shorter R3 $3^{388-404}$ peptide or to the R1-R2$\mathrm{R}^{325-404}$ peptide, the $\mathrm{R} 3^{381-404 \mathrm{~W}}$ peptide showed re-appearance of all resonances at the latest titration steps with UFC1 (Figure 2D and Supplementary Figure S3E). Correspondingly, almost all backbone amide resonances of UFC1 became visible at the latest stages of titration with R3 $381-404 \mathrm{~W}$ (Figure $2 \mathrm{E}$ and Supplementary Figure S3F), enabling us to solve the UFC1:R3 ${ }^{381-404 \mathrm{~W}}$ complex structure. The structure is presented in Figure 3 and Supplementary Figure S4, structural statistics are given in Supplementary Table S1. The UFC1 structure in complex with the $\mathrm{R}^{381-404 \mathrm{~W}}$ peptide is close to the previously published X-ray and NMR structures of free UFC1 (Supplementary Figure S4A, [11,35]). The most significant differences were observed in the orientation of the $\mathrm{N}$-terminal $\alpha$-helix $\alpha 1$ (residues 1-11), the conformation of the C-terminal UFC1 part (residues 156-167) and the flexible loop near the active-cite cysteine 116 (residues 91-124, Supplementary Figure S4B). 

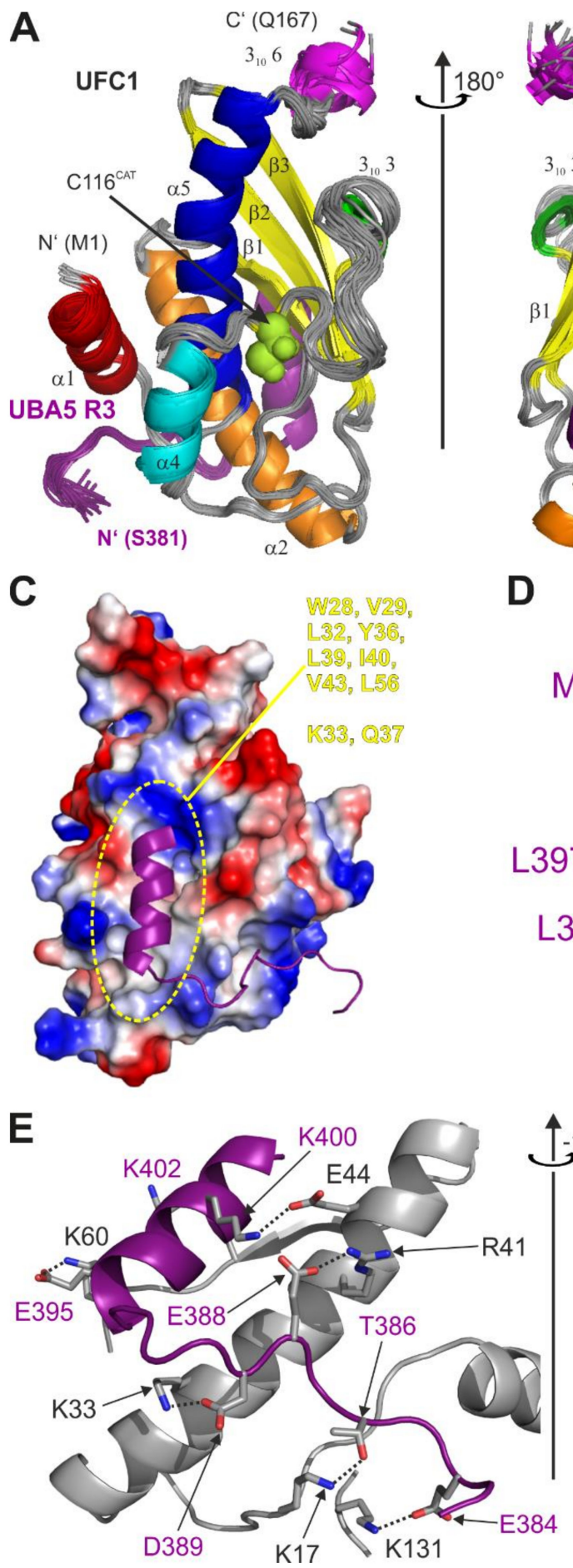
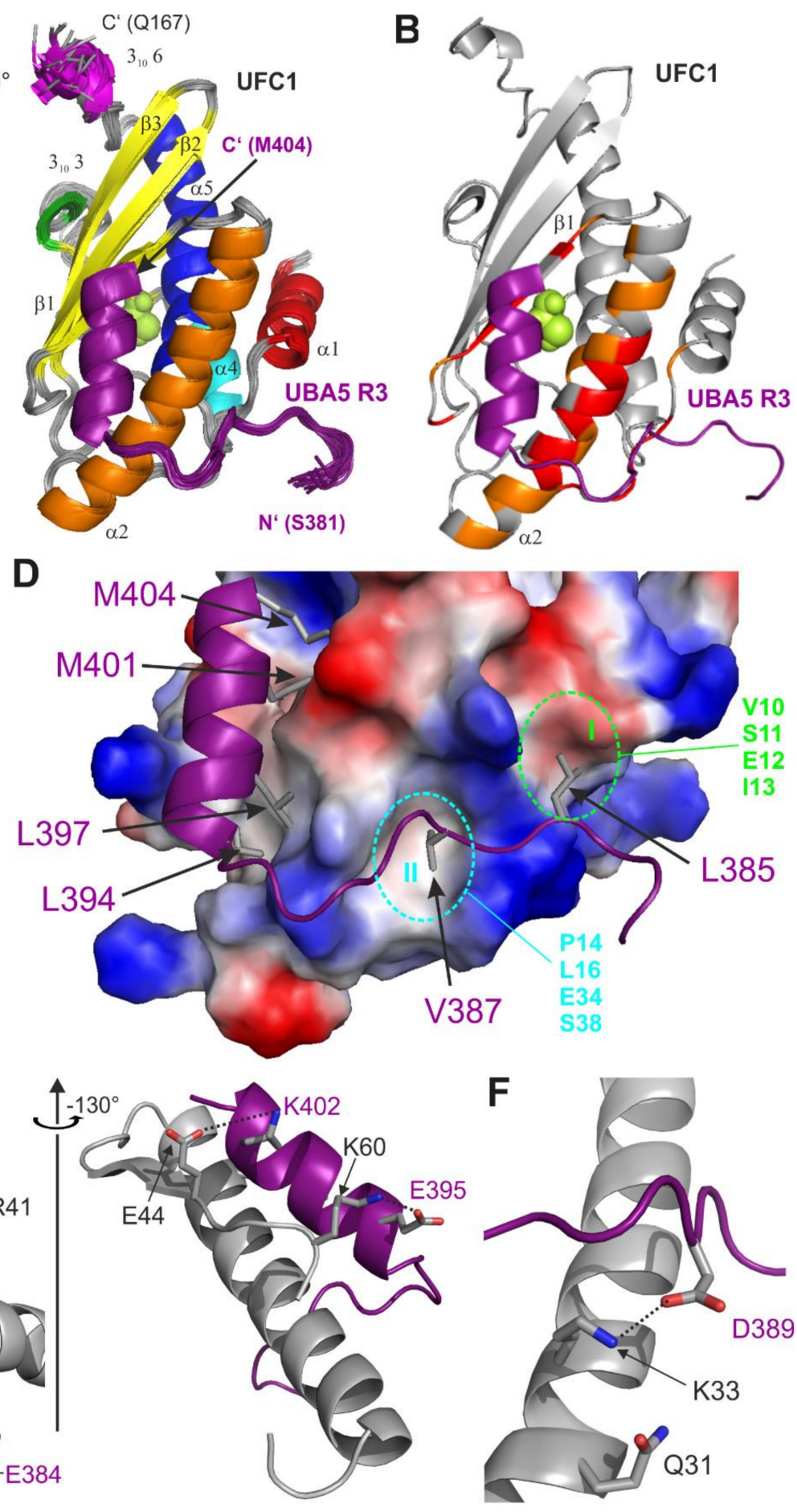

Figure 3. NMR structure of the complex between UFC1 and the UBA5 R3 $381-404 \mathrm{~W}$ peptide. (A) NMR solution structure of the complex between UFC1 and R $3^{381-404 \mathrm{~W}}$ peptide in two different orientations. All 20 conformers are superimposed over the structured UFC1 core (residues 3-162). All UFC1 secondary structure elements are marked by the following colors: $\alpha 1$-red; $\alpha 2$-orange; $3^{10}$ helix 3 -green; $\alpha 4$-cyan, $\alpha 5$-blue; $3^{10}$ helix 6 -magenta; all $\beta$-strands $(\beta 1, \beta 2, \beta 3)$ are yellow. $\mathrm{R} 3^{381-404 \mathrm{~W}}$ chains are shown in purple. (B) Mapping of UFC1 CSPs upon titration with $\mathrm{R} 3^{381-404 \mathrm{~W}}$ on a representative complex structure (conformer 6, the same orientation as in the A, right plot). The CSP values below standard deviation (SD), between 1xSD and 2xSD, and above 2xSD are labeled grey, yellow and red, respectively. Residues which were not assigned are presented in grey as well. (C) UFC1 molecule (conformer 6, the same orientation as in the A, right plot) is shown as a surface with calculated potentials, whereas the $\mathrm{R} 3^{381-404 \mathrm{~W}}$ molecule is presented by ribbon diagram (purple). The large hydrophobic groove between UFC1 $\alpha$-helix $\alpha 2$ and $\beta$-strand $\beta 1$ is highlighted with a dashed yellow line. UFC1 residues 
contributing to the groove formation are listed. (D) Hydrophobic patches on UFC1 surface mediating interactions with the UBA5 R3 ${ }^{381-404 W}$ L385 and V387 side chains are shown as grey sticks. The UFC1 hydrophobic patches I and II are marked with dashed lines (green and magenta, respectively). UFC1 residues forming these patches are listed. (E) Polar interactions within the UFC1:R3 ${ }^{381-404 \mathrm{~W}}$ complex. Intermolecular hydrogen bonds are shown as dashed lines. (F) Detailed view on the intermolecular hydrogen bond between UBA5 D389 and UFC1 K33. The UBA5 Q31 sidechain is also presented as sticks.

Residues 394-404 of the R3 region form the predicted [32] $\alpha$-helix, residues 384-392 are in an extended conformation, well-defined and occupy a specific area on the UFC1 surface. Residues 381-383 seem disordered and do not interact specifically with any UFC1 residues. The amphiphilic R3 $\alpha$-helix is aligned to the $\alpha 2 \alpha$-helix of UFC1 (Figure 3A) on the side opposite to the catalytic cysteine (C116). The UFC1 resonances on the C116 side were not affected upon NMR titration experiments, leading to the suggestion that this side could interact with the adenylation domain during UFM1 transfer. Sidechains of the R3 $3^{381-404 W}$ hydrophobic residues (L394, L397, M401 and M404) are placed into the large hydrophobic cleft formed by $\alpha$-helix $\alpha 2$ and $\beta$-strand $\beta 1$ of UFC1 (residues W28, V29, L32, Y36, L39, I40, V43, L56 and aliphatic moieties of K33 and Q37; Figure 3C). Two additional hydrophobic patches I and II (formed by residues within $\alpha$-helices $\alpha 1, \alpha 2$ and the loop between them) accommodate UBA5 residues L385 and V386 (Figure 3D).

In addition to intermolecular hydrophobic interactions, the complex between UFC1 and the $\mathrm{R} 3^{381-404 \mathrm{~W}}$ peptide is stabilized by a network of intermolecular hydrogen bonds and polar contacts (Figure 3E, all intermolecular contacts detected by the LigPlot software for the UFC1:R3 ${ }^{381-404 \mathrm{~W}}$ complex are shown in Supplementary Figure S4C). The network covers almost all residues within the R3 region, which interact with the polar residues of UFC1 in the same area- $\alpha 1, \alpha 2$, loop between them and $\beta$-strand $\beta 1$ (detailed information on the polar contacts is given in the Supplementary Figure S4C). The only additional UFC1 residue that forms intermolecular hydrogen bonds to the $\mathrm{R} 3^{381-404 \mathrm{~W}}$ peptide outside of this UFC1 region, is K131, whose sidechain is in close proximity to the carboxyl group of UBA5 E384.

Previously, it was predicted that the UFC1:UBA5 interaction is mediated by the UFC1 $\alpha$-helix $\alpha 2$ [11] and the point mutation K33A within this helix impaired UBA5 binding and UFM1 transfer to UFC1, whereas Q31A had no effect. In our structure we observed that the UFC1 K33 sidechain forms an intermolecular hydrogen bond with the UBA5 D389 sidechain (Figure 3F). In contrast, UFC1 Q31 is not in contact with any of the UBA5 R3 residue and could not affect the UBA5:UFC1 interaction.

In summary, the structure of UFC 1 in complex with the R $3^{381-404 \mathrm{~W}}$ peptide revealed that the C-terminal $\alpha$-helical part of UBA5 is pivotal for the attraction of UFC1 to UBA5. In addition to the $\alpha$-helical part, UBA5 residues L385 and V387 also play a role in the UBA5 interaction with UFC1. The UFC1 hydrophobic groove and hydrophobic patches I and II are the most important areas mediating the interaction. Intermolecular polar contacts and hydrogen bonds stabilize the observed complex. The sidechain of UFC1 K33 is involved in an intermolecular hydrogen bond formation (to UBA5 D389 as a counterpart), therefore, its substitution to alanine interferes with the UFC1 interaction to UBA5 [11].

\subsection{Interactions within the Ufmylation Cascade}

Our results so far describe the interaction of UFC1 with the UBA5 C-terminal region. However, the interaction between full length UBA5 and UFC1 could be more complex and could depend on UFM1 conjugation to UBA5 or UFC1. To answer the question if UBA5 can bind UFC1 via additional sites, we analyzed NMR spectra of UFC1 with a 2-fold excess of unlabeled UBA5 FL ${ }^{1-404}$. We did not observe significant CSPs (shift or disappearance of the UFC1 resonances) in comparison to the spectra of the UFC1:R3 $3^{381-404 \mathrm{~W}}$ complex (Supplementary Figure S5A).

Additionally, UBA5 lacking the R3 region $\left(\triangle \mathrm{R} 3^{1-380}\right)$ did not interact with UFC1 (as observed by NMR titration experiment, Supplementary Figure S5B) and significantly slowed down UFM1 transfer to UFC1 (Figure 4A, Supplementary Figure S5D). All these observations indicate that besides R3, UFC1 does not bind to any UBA5 regions efficiently. 
However, even weak additional interactions could facilitate the UFC1 UFM1 conjugation as observed in this work for the UBA5 constructs lacking R3 (Figures 1C and 4A, Supplementary Figure S1).
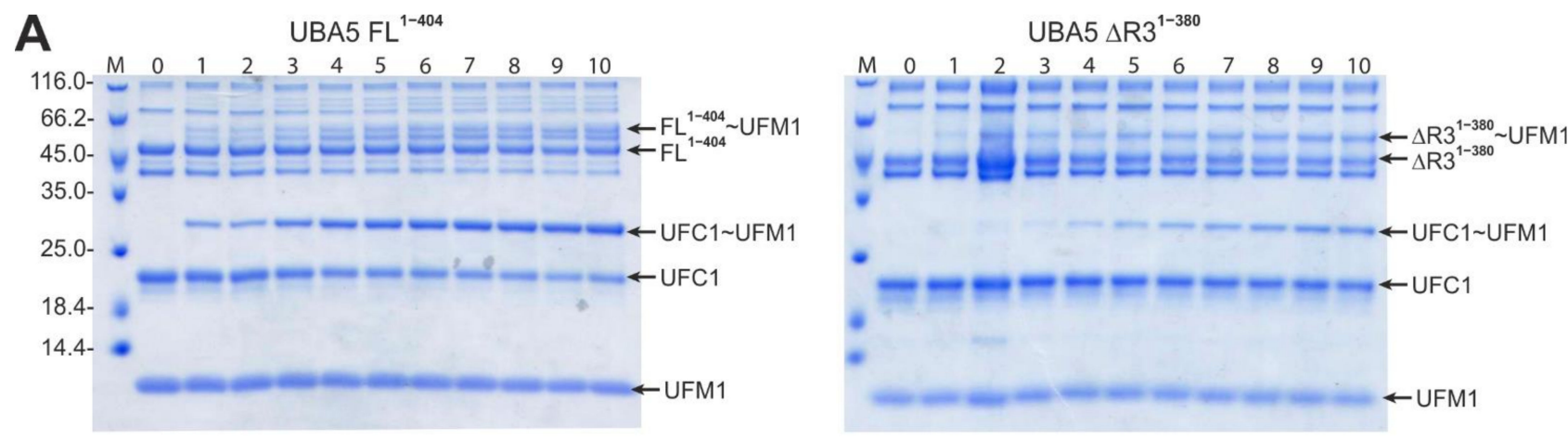

B

UBA5 $\mathrm{FL}^{1-404} \mathrm{C} 250 \mathrm{~K} \sim \mathrm{UFM} 1$

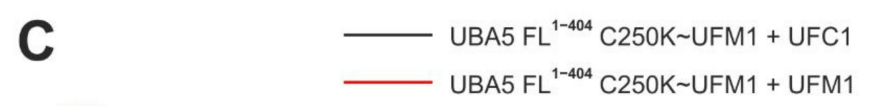
Time (min)

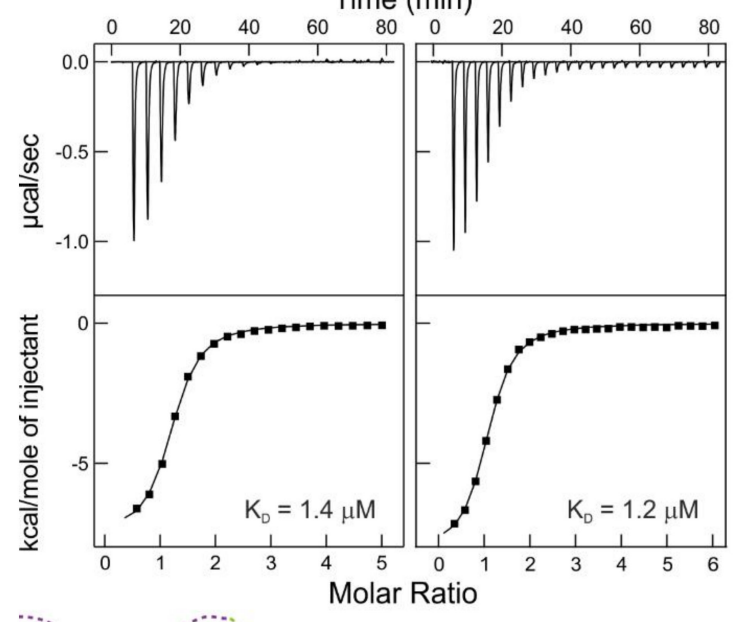

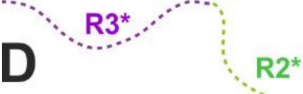
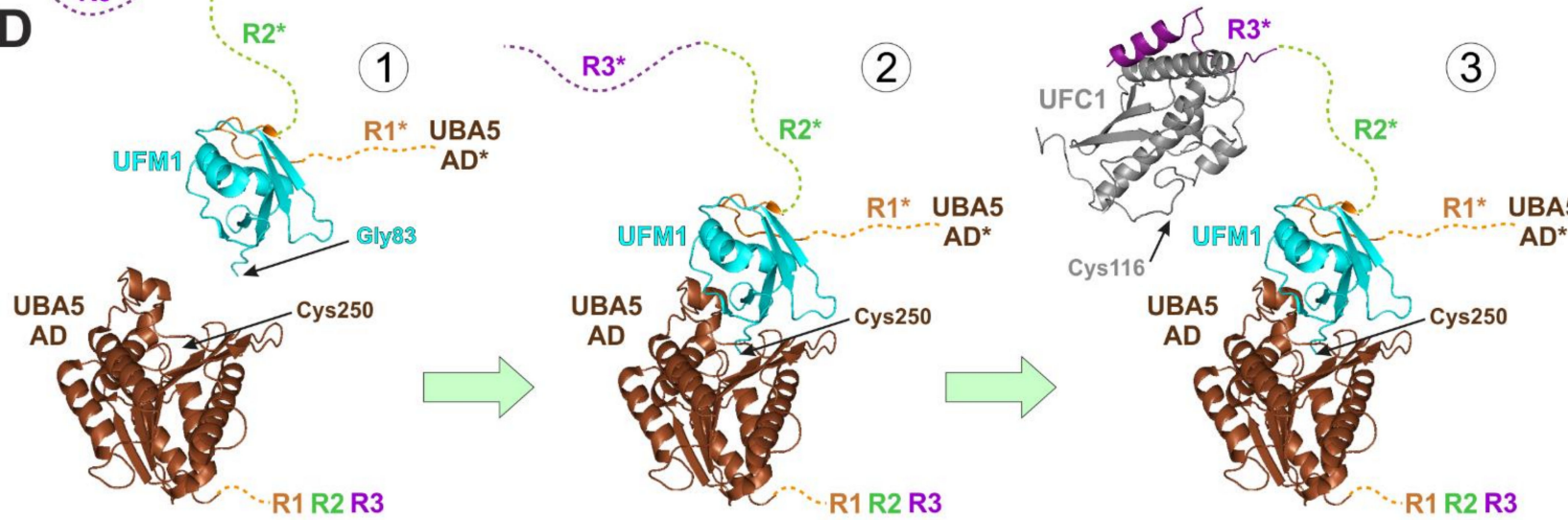

Figure 4. Interaction studies between full length UBA5 and UFC1 proteins. (A) Gel electrophoresis of ufmylation assays including UBA5 $\mathrm{FL}^{1-404}$ (left plot) and UBA5 $\triangle \mathrm{R}^{1-380}$. (B) UFC1 binding to full length UBA5 (left plot) and full length stable UBA5 UFM1 conjugate (right plot) observed by ITC experiments. The upper graph displays the raw heat data; the lower graph shows the integrated heat per titration steps (black squares) with best-fit curve (line). $K_{D}$ values are indicated. (C) Gel-filtration profiles of the FL ${ }^{1-404}$ C250K UFM1 conjugates in presence of 4 times molar excess of UFM1 (red lines) and UFC1 (black lines). The peak subjected to electrophoretic analysis is indicated by an asterisk. (D) Scheme of reactions involving UBA5 in the ufmylation cascade. The structures of UBA5 AD (brown), UFM1 (cyan) and UFC1 (grey) are represented as ribbon diagrams; the UBA5 unstructured C-terminus containing regions R1 (orange), R2 (green) and R3 (violet) is shown as dashed lines. The structures were generated from PDB entry 5IAA [29]. * indicates regions of another UBA5 molecule involved in the in trans transfer of UFM1. 
To investigate if conjugation of UFM1 to the UBA5 catalytic cysteine (C250) affects the UFC1:UBA5 interactions, we prepared full length UBA5 C250K mutant and stably conjugated UFM1 to it as reported before for a number of ubiquitin-specific E2 enzymes [38-40]. We compared the UFC1 spectra after addition of a twofold molar excess of FL ${ }^{1-404}$ and FL $^{1-404}$ C250K UFM1 constructs (Supplementary Figure S5C). Again, no significant enhancement of the UBA5:UFC1 interaction induced by the UBA5 UFM1 conjugation was observed. ITC experiments, in which we titrated UFC1 to FL ${ }^{1-404}$ and to FL ${ }^{1-404}$ C250K UFM1 samples (Figure 4B, Table 2), showed small increases in their affinity to UFC1 in comparison to the R1-R2-R3 ${ }^{325-404}$ peptide ( $\mathrm{K}_{\mathrm{D}}$ values for R1-R2-R3 ${ }^{325-404}$, FL ${ }^{1-404}$, FL ${ }^{1-404}$ C250K UFM1 are 2.4, 1.4 and $1.2 \mu \mathrm{M}$, respectively).

UFM1 conjugation to UBA5 C250 did not prohibit UFM1 binding to the R1 region. The gel-filtration profile and following electrophoretic analysis of the fractions showed that the $\mathrm{FL}^{1-404} \mathrm{C} 250 \mathrm{~K} \sim \mathrm{UFM} 1$ but not the $\mathrm{AD}^{1-330} \mathrm{C} 250 \mathrm{~K} \sim \mathrm{UFM} 1$ peak contains non-conjugated UFM1 (Figure 4C and Supplementary Figure S5E).

\section{Discussion}

In this paper we analyzed the interactions between UBA5 and UFC1 enzymes within the ufmylation cascade and found that the unstructured UBA5 C-terminal part provides a platform for multiple protein-protein interactions affecting the efficiency of the activated UFM1 transfer from UBA5 to UFC1.

\subsection{The UFC1:UBA5 Interaction}

Our ITC and NMR titration experiments revealed that the interaction between UFC1 and UBA5 is mediated mostly by the relatively short and evolutionary conserved stretch of UBA5 residues (383-404). Using the optimized UBA5 construct (R3 ${ }^{381-404 W}$ peptide), we solved the NMR structure of the UFC1:R3 complex. The complex structure in combination with the NMR and ITC titration experiments revealed that in addition to the core R3 region, residues in the region $\mathrm{R} 2$ contribute to the interaction. While the isolated $\mathrm{R} 2$ peptide does not interact with UFC1, the combination of R2 and R3 binds three times tighter than the R3 alone. This weak additional interaction also explains the results of the UFC1 ufmylation assay (Figure 1). Ability of the isolated UBA5 AD to transfer activated UFM1 on UFC1 gets rescued by addition of the R1-R2-R3 peptide. In this peptide the R1 sequence can bind to UFM1 conjugated to UBA5 and recruit via its exposed R3 peptide UFC1 to the complex (Figure 4D). In full length UBA5 this recruitment occurs similarly, resulting in very similar UFC1 ufmylation rates. Adding only the R2-R3 peptide to the UBA5 AD increases the reaction rate only slightly above the isolated individual R1, R2 or R3 peptides, because deletion of the R1 sequence prevents effective recruitment of UBA5 C-terminus in complex with UFC1 to the UFM1-charged AD. A stronger rescue effect is seen for the R1-R2 peptide, because the R2 peptide probably still can interact with UFC1 (Figure 2C) and thus increase the local concentration of UFC1 around the AD. In the full length UBA5 protein, this recruiting effect most likely occurs in-trans [29]. A dimer was found in the crystal structure of UBA5 in complex with UFM1 bound to the R1 region. The linker between the $\mathrm{AD}$ and the R1 sequence is too short for an in-cis transfer to the active site cysteine, but within the dimer UFM1 bound to R1 of one monomer can be adenylated by the other UBA5 molecule of the dimer. This mechanism was confirmed by clever mutational engineering showing that a forced monomer cannot activate UFM1. Similarly, a trans mechanism was proposed for the transfer to UFC1 as well (Figure 4D). In our NMR titration experiments the UFC1 catalytic cysteine C116 and neighboring residues were not affected upon titration with the R3 peptide and our complex structure revealed that the R3 peptide occupies the side of the UFC1 molecule opposite to C116, indicating that the UFC1 surface around C116 could be used by the UBA5 AD during UFM1 transfer. Note that our data alone did not exclude in-cis UFM1 transfer mode.

In general, we were able to observe relatively stable interactions between members of the ufmylation cascade only for the R1:UFM1 and R3:UFC1 interactions. All other 
interactions are so weak that they are hard to detect by NMR (additional R2 residues with UFC1) or cannot be characterized at all. This includes interaction of UFC1 with the UBA5 AD alone or charged with UFM1 as well as with isolated UFM1. These results suggest that transfer of UFM1 from the adenylation domain of UBA5 to UFC1 uses in addition to relatively strong interactions for recruitment of the necessary components very weak interactions for the transfer (hit-and-run model).

\subsection{Interaction between GABARAPL2 and UBA5 C-Terminal Part}

The GABARAP and LC3 subfamilies members were found to bind UBA5 via an atypical LIR (LIR/UFIM), an evolutionary conserved sequence within the UBA5 C-terminal part [31,33]. The ITC and NMR experiments revealed additional interactions next to the known binding site within the R1. UBA5 constructs including both R1 and R2 regions showed a 10fold higher binding affinity to all GABARAP and LC3 protein subfamily members. Binding preference towards the GABARAP subfamily proteins remains preserved $[31,33]$. NMR titration experiments disclosed a more complex binding mechanism of GABARAPL2 to the complete C-terminal UBA5 peptide. At earlier titration steps, UBA5 residues within R1 were strongly affected by GABARAPL2 binding. However, with increasing concentrations of GABARAPL2 conserved residues located mostly in R2 started to display significant CSPs as well. These additional interactions might become relevant when UBA5 gets recruited to a membrane and GABARAP proteins cluster in micro-domains. A high concentration of GABARAP proteins in combination with a reduction of the search space for interactions from three to two dimensions could allow simultaneous binding of several GABARAP proteins to the UBA5 C-terminus. Recruitment of UBA5 to the membrane of the endoplasmic reticulum (ER) has been observed [33], the exact role of this recruitment is subject for further investigations.

\subsection{The Role of the A371T Mutation in the Ufmylation Cascade}

Many diseases are associated with impaired ufmylation [16,21-24]. Ufmylation is essential for embryonic development [25-27]. The A371T mutation was described previously to be present in patients suffering from severe infantile-onset encephalopathy [25,34]. Further investigations showed slightly reduced UBA5 thioester conjugation with UFM1 and reduced enzymatic activity in trans-thioesterification of UFC1 in vivo for the UBA5 A371T mutant $[25,34]$. Our ITC experiments with C-terminal UBA5 peptides containing the A371T or its phosphomimicking A371E mutations (located in the R2 region) showed almost no influence on UFM1:UFC1 binding affinity. NMR titration of the wild type ${ }^{15}$ N-labeled R1-R2-R3 ${ }^{325-404}$ peptide with UFC1 displayed some moderate CSPs for the A371 and residues around, indicating a minor role of the R2 sequence in UFC1 binding. In vitro ufmylation assays showed that R1-R2-R3 ${ }^{325-404}$ A371T and R1-R2-R3 ${ }^{325-404}$ A371E peptides have nearly the same trans-thioesterification efficiency compared to wild type R1-R2-R3 ${ }^{325-404}$ peptide in standard ufmylation assay conditions. However, reduction of ATP (to $25 \mu \mathrm{M}$ ) led to a reduction of the UFC1 UFM1 conjugate fraction for both mutated UBA5 peptides in comparison to wild type peptide, as reported previously [25,34].

Interestingly, we detected an increased affinity of R1-R2-R3 ${ }^{325-404}$ A371T and R1-R2$\mathrm{R}^{325-404}$ A371E peptides to GABARAPL2 and LC3B proteins in ITC experiments. While GABARAPL2 showed a $\sim 3$-fold increased affinity to both mutated peptides in comparison to the wild type peptide, we detected a $~ 7$-fold increased affinity for LC3B to the A371E mutant and a $\sim 3$-fold increased affinity to the A371T mutant. NMR titration experiments with wild type R1-R2-R3 $325-404$ peptide revealed that A371 and adjacent residues are involved in GABARAPL2 binding at high GABARAPL2 concentrations. Again, taking into account that GABARAP and LC3 protein family members are proposed to recruit UBA5 to the ER membrane and play a critical role in the regulation of the ufmylation pathway $[33,41]$, these results lead to the assumption that the A371T mutation plays a minor role in the ufmylation reaction itself, but might affect UBA5 localization and thus influences target ufmylation. 


\section{Materials and Methods}

\subsection{DNA Constructs Used in This Study}

Genes of proteins and UBA5 peptides were cloned into a pET39_Ub19 vector containing a modified ubiquitin tag [33] and a TEV cleavage site resulting in a $\mathrm{N}$-terminal cloning artefact of the first three residues (GAM). UBA5 C250K and UFC1_His6 were cloned into pNiC-CTH0 vector with a C-terminal hexahistidine-tag cleavable by an introduced TEV cleavage site. For site-directed mutagenesis PfuUltra II fusion HS DNA polymerase (Agilent Technologies Germany, Frankfurt, Germany) was used according to the manufacturer's instructions. A comprehensive list of DNA constructs used in this study is given in Table 1.

\subsection{Expression, Isolation and Purification of the Peptides and Proteins}

All proteins and peptides were expressed in E.Coli T7 Express (New England Biolabs GmbH, Frankfurt, Germany) cells in LB or M9 (to obtain ${ }^{15} \mathrm{~N}$ - and ${ }^{13} \mathrm{C},{ }^{15} \mathrm{~N}$-labeled polypeptides) media according to the protocol described in $[33,36]$. For protein purification, bacterial cell pellets were resuspended in lysis buffer $(50 \mathrm{mM}$ Tris- $\mathrm{HCl} \mathrm{pH}=7.5$, $100 \mathrm{mM} \mathrm{NaCl}, 5 \%$ glycerol, $5 \mathrm{mM}$ PIC (protease inhibitor cocktail)) and lysed via sonication (TT13 Sonotrode, $40 \%$ amplitude, for $6 \times 1 \mathrm{~min}$ with a $0.5 / 0.5$-s pulse). Lysates were centrifuged for $45 \mathrm{~min}$ at $17,000 \times g$ at $4{ }^{\circ} \mathrm{C}$. Supernatants were loaded onto a His Trap Fast Flow $5 \mathrm{~mL}$ column (GE Healthcare, München, Germany) equilibrated in loading buffer (50 mM Tris- $\mathrm{HCl} \mathrm{pH} \mathrm{=} \mathrm{8.0,} 250 \mathrm{mM} \mathrm{NaCl}, 1 \%$ glycerol, $20 \mathrm{mM}$ imidazole). The column was washed with loading buffer for $5-10 \mathrm{CV}$ and protein was eluted with elution buffer (50 mM Tris- $\mathrm{HCl} \mathrm{pH}=8,250 \mathrm{mM} \mathrm{NaCl}, 1 \%$ glycerol, $400 \mathrm{mM}$ imidazole). Simultaneous TEV cleavage ( $1 \mathrm{mg}$ TEV protease was added to $100 \mathrm{mg}$ peptides/proteins) and buffer exchange to loading buffer via dialysis was performed over night at $4{ }^{\circ} \mathrm{C}$. After reverse IMAC, proteins were concentrated with conical concentrators (Millipore Merck, Darmstadt, Germany) and loaded on a Superdex 10/60 75 or 200 column (GE Healthcare, München, Germany) for further purification and equilibration with ITC/NMR buffer ( $25 \mathrm{mM}$ HEPES $\mathrm{pH}=7.5,100 \mathrm{mM} \mathrm{NaCl}$ ). For structural NMR spectroscopy, buffer containing $50 \mathrm{mM}$ Tris- $\mathrm{HCl} \mathrm{pH}=7.5,100 \mathrm{mM} \mathrm{NaCl}$ was used. Prior to NMR experiments, TCEP and protease inhibitors cocktail were added to the samples to final concentrations 1 and $5 \mathrm{mM}$, respectively. Purified peptides and protein were concentrated and stored at $-80^{\circ} \mathrm{C}$. The protein and peptide concentrations were calculated from the UV absorption at $280 \mathrm{~nm}$ by Nanodrop spectrophotometer (Thermo Scientific, Langenselbold, Germany).

\subsection{In Vitro Thioester Formation Assay}

Ufmylation reaction assays were adopted from work of Xie [32]. Briefly, $70 \mu \mathrm{M}$ UFM1, $20 \mu \mathrm{M} \mathrm{UFC} 1$ and $20 \mu \mathrm{M}$ of different UBA5 constructs were mixed in reaction buffer $(50 \mathrm{mM}$ HEPES $\mathrm{pH}=7.5,100 \mathrm{mM} \mathrm{NaCl}, 5 \mathrm{mM} \mathrm{MgCl}_{2}$ ). After starting the reaction with addition of $1 \mathrm{mM}$ ATP, the reaction mix was incubated at $22{ }^{\circ} \mathrm{C}$ for the desired time. To quench the reaction and prepare electrophoretic samples, $1 \mu \mathrm{L}$ of the reaction mix was added to $99 \mu \mathrm{L}$ $1 \mathrm{x}$ non-reducing SDS loading buffer and frozen in liquid nitrogen. Sample content was visualized by sodium dodecyl sulfate polyacrylamide gel electrophoresis (SDS-PAGE). The transfer to polyvinylidene difluoride (PVDF) membrane was performed via a Trans-Blot ${ }^{\circledR}$ Turbo $^{\mathrm{TM}}$ Transfer System (Bio-Rad, München, Germany). After transfer the membrane was blocked with TBST (Tris-buffered saline with Tween20 buffer, $20 \mathrm{mM}$ Tris, $150 \mathrm{mM} \mathrm{NaCl}$ and $0.1 \%$ TWEEN 20 ) containing $5 \% w / v$ nonfat dry milk for $1 \mathrm{~h}$, followed by $\alpha$-UFC1 antibody incubation over night at $4{ }^{\circ} \mathrm{C}$ (ab189251 abcam, 1:10,000 in TBST containing $5 \% w / v$ nonfat dry milk). After washing with TBST the membrane was incubated with secondary antibody (anti-rabbit-HRP) for $1 \mathrm{~h}$ at RT and again washed with TBST. Detection was performed by addition of ECL solution. For quantification of UFC1 ufmylation coloc2 software implemented in ImageJ was used. To show the kinetic differences between $\mathrm{FL}^{1-404}$ and $\triangle \mathrm{R} 3^{1-380}$ on UFC1 ufmylation, the reactions were started with $25 \mu \mathrm{M}$ ATP.

For stable UBA5 UFM1 conjugation, $70 \mu \mathrm{M}$ UFM1, $20 \mu \mathrm{M} \mathrm{FL}^{1-404} \mathrm{C} 250 \mathrm{~K}$ and $1 \mathrm{mM}$ ATP were added to ufmylation reaction buffer (50 mM HEPES $\mathrm{pH}=10.0,100 \mathrm{mM} \mathrm{NaCl}$, 
$5 \mathrm{mM} \mathrm{MgCl} 2$ ). For NMR analysis, resulting complexes were concentrated and equilibrated with ITC/NMR buffer. To analyze complex formation by ufmylation assay $300 \mu \mathrm{L}$ of sample were loaded onto a Superdex 200 10/300 column (GE Healthcare, München, Germany).

\subsection{Isothermal Titration Calorimetry}

All ITC experiments were performed at $25{ }^{\circ} \mathrm{C}$ using a VP-ITC microcalorimeter (Malvern Panalytical Ltd., Malvern, UK). Peptides in concentration of $\sim 400 \mu \mathrm{M}$ were titrated into 20-25 $\mu \mathrm{M}$ solutions of corresponding binding partner at a stirring speed of $307 \mathrm{rpm}$. The raw data were corrected on the dilution heat of peptides obtained in independent experiment (titration of the peptide in syringe into the ITC/NMR buffer in the measuring cell). Pre-titration delay was set to $180 \mathrm{~s}$, interval between titration steps was experimentally adjusted to avoid kinetic contribution to the observed heat effects and set to $200 \mathrm{~s}$. A single ITC profile was collected for each type of interaction. The ITC data were analyzed based on a "one-site" binding model with MicroCal ITC software implemented in Origin 7.0.

\subsection{NMR Spectroscopy}

All NMR experiments were performed at a sample temperature of $25{ }^{\circ} \mathrm{C}$ on Bruker $600,700,800,900$, and $950 \mathrm{MHz}$ spectrometers equipped with cryogenic probes, and a $500 \mathrm{MHz}$ spectrometer equipped with a room-temperature triple-resonance probe. All NMR spectra were analyzed with the Sparky 3.114 software (University of California, San Francisco, USA). For NMR titration experiments, the non-labeled UBA5 peptides were titrated to $100 \mu \mathrm{M}{ }^{13} \mathrm{C}^{15} \mathrm{~N}$-labeled UFC1 to a final molar ratio of 1:8 (UFC1:UBA5 peptide). Conversely, $100 \mu \mathrm{M}^{13} \mathrm{C},{ }^{15} \mathrm{~N}$-labeled UBA5 peptides were titrated with non-labeled UFC1 to a final molar ratio 1:4 (UBA5 peptide:UFC1). $2 \mathrm{D}^{1} \mathrm{H}_{-}{ }^{15} \mathrm{~N}$ correlation spectra $\left(\left[{ }^{15} \mathrm{~N},{ }^{1} \mathrm{H}\right]\right.$ TROSY-HSQC) were recorded at each titration point. The same types of spectra were recorded to estimate binding of ${ }^{13} \mathrm{C},{ }^{15} \mathrm{~N}$-labeled UFC1 $(75 \mu \mathrm{M})$ to non-labeled UBA5, UBA5 UFM1 and UFM1 at 1:2 molar ratios. CSP values, $\Delta \delta$, were calculated for each individual amide group using the formula $\left.\Delta \delta=\left[\left(\Delta \delta_{\mathrm{N}} / 5\right)^{2}+\Delta \delta^{2} \mathrm{HN}\right)\right]^{1 / 2}$.

For structural NMR spectroscopy, samples containing $1 \mathrm{mM}{ }^{13} \mathrm{C},{ }^{15} \mathrm{~N}$-labeled UFC1 in the presence of $1 \mathrm{mM}$ non-labeled $\mathrm{R}^{381-404 \mathrm{~W}}$ and $0.3 \mathrm{mM}{ }^{13} \mathrm{C}^{15} \mathrm{~N}$-labeled $\mathrm{R} 3^{381-404 \mathrm{~W}}$ in presence of $1.2 \mathrm{mM}$ non-labeled UFC1 were used. As buffer condition $50 \mathrm{mM}$ Tris $\mathrm{pH}=7.5,100 \mathrm{mM} \mathrm{NaCl}, 2 \mathrm{mM}$ TCEP, $5 \mathrm{mM}$ PIC, 5\% D2O, $0.15 \mathrm{mM}$ DSS was chosen. Backbone resonance assignment was performed using 3D BEST-TROSY versions [42,43] of $\mathrm{HNCACB}, \mathrm{HNCO}, \mathrm{HN}(\mathrm{CO}) \mathrm{CACB}$ and $\mathrm{HN}(\mathrm{CA}) \mathrm{CO}$ pulse sequences. Aliphatic ${ }^{1} \mathrm{H}$ and ${ }^{13} \mathrm{C}$ side-chain assignments resulted from $(\mathrm{H}) \mathrm{CC}(\mathrm{CO}) \mathrm{NH}-\mathrm{TOCSY}$, and $\mathrm{H}(\mathrm{CCCO}) \mathrm{NH}-\mathrm{TOCSY}$ experiments $[44,45]$. The assignment of aromatic side chain resonances was accomplished with amino-acid type specific versions of the (H)CB(CGCC-TOCSY)H $\mathrm{H}^{\text {ar }}$ experiment [46] in conjunction with a $\left[{ }^{13} \mathrm{C},{ }^{1} \mathrm{H}\right]$-ct-TROSY experiment $[47,48]$ and an aromatic ${ }^{13} \mathrm{C}$-resolved $3 \mathrm{D}$ NOESY-SOFAST-HMQC experiment was used for verification. To obtain distance restrains for structure calculations $3 \mathrm{D}^{15} \mathrm{~N}$ - and ${ }^{13} \mathrm{C}$ - separated NOESY-HSQC spectra, recorded with a mixing time of $60 \mathrm{~ms}$, were analyzed. To obtain intermolecular distance restrains, 3D F1- ${ }^{13} \mathrm{C} /{ }^{15} \mathrm{~N}$-filtered NOESY- $\left[{ }^{13} \mathrm{C}_{\mathrm{ali}},{ }^{1} \mathrm{H}\right]-\mathrm{HSQC}$, NOESY- $\left[{ }^{13} \mathrm{C}_{\text {aro }},{ }^{1} \mathrm{H}\right]-S O F A S T-H M Q C$ and NOESY- $\left[{ }^{15} \mathrm{~N},{ }^{1} \mathrm{H}\right]-S O F A S T-H M Q C$ experiments (mixing time $150 \mathrm{~ms}$ ) were performed [49]. The structure was calculated via CYANA [50] version 3.98 with automated peak assignment. Torsion angles were predicted based on chemical shift values by PREDITOR program [51]. Restrained energy refinement using OPALp [52] was performed for the 20 conformers with the lowest final CYANA target function.

The 20 energy-refined conformers were deposited in the Protein Data Bank with accession code 7OVC. The chemical shift assignments were deposited in the BioMagResBank (BMRB) database with accession code 34638. 
Supplementary Materials: The following are available online at https:/ /www.mdpi.com/article/ 10.3390/ijms22147390/s1, Figure S1: UFC1 ufmylation mediated by different UBA5 constructs, Figure S2: Interaction between UBA5 C-terminal constructs and UBA5 interacting proteins observed by ITC experiments, Figure S3: Interactions between UBA5 C-terminal constructs and UBA5-interacting proteins observed by NMR titration experiments, Figure S4: Structural features of the UFC1:UBA5 R3 complex, Figure S5: UFC1 binding to the full length UBA5 and UBA5 UFM1 complex, Table S1: NMR and refinement statistics for the UFC1:UBA5 R3 ${ }^{381-404 \mathrm{~W}}$ complex.

Author Contributions: V.V.R. design and led the project. N.W., V.D. and V.V.R. wrote the paper. The ITC and NMR experiment were designed by V.V.R. and V.D. and were performed by N.W. and F.L. Constructs were designed by N.W. and V.V.R. and prepared by N.W. and N.R. Ufmylation assays were performed by N.W. with contribution of N.R. Structural calculations were performed by V.V.R and N.W. All authors commented on final draft of the paper. All authors have read and agreed to the published version of the manuscript.

Funding: F.L., V.D. and V.V.R was supported by the DFG-funded Collaborative Research Centre on Selective Autophagy (SFB 1177 "Molecular and Functional Characterization of Selective Autophagy"), Germany. V.D. and V.V.R. also received funding from Structural Genomic Consortium. The Structural Genomics Consortium is a registered charity (no: 1097737) that receives funds from Bayer AG, Boehringer Ingelheim, Bristol Myers Squibb, Genentech, Genome Canada through Ontario Genomics Institute [OGI-196], EU/EFPIA/OICR/McGill/KTH/Diamond Innovative Medicines Initiative 2 Joint Undertaking [EUbOPEN grant 875510], Janssen, Merck KGaA (aka EMD in Canada and US), Pfizer and Takeda.

Institutional Review Board Statement: Not applicable.

Informed Consent Statement: Not applicable.

Data Availability Statement: The structure of UFC1:UBA5 R3 complex was deposited in the Protein Data Bank (https: / /www.rcsb.org/) (accessed on 7 July 2021) with accession code 7OVC. The chemical shift assignments were deposited in the BioMagResBank database (https:/ / bmrb.io) (accessed on 7 July 2021) with accession code 34638.

Conflicts of Interest: The authors declare no conflict of interest.

$\begin{array}{ll}\text { Abbreviations } \\ \text { AD } & \text { UBA5 adenylation domain } \\ \text { ASC1 } & \text { activating signal co-integrator 1 } \\ \text { ATP } & \text { adenosine triphosphate } \\ \text { BEST } & \text { band-selective excitation short-transient } \\ \text { CSP } & \text { chemical shift perturbation } \\ \text { FL } & \text { full length } \\ \text { GABARAP } & \text { GABA A-receptor-associated protein } \\ \text { HMQC } & \text { heteronuclear multiple quantum coherence } \\ \text { HSQC } & \text { heteronuclear single quantum coherence } \\ \text { ITC } & \text { isothermal titration calorimetry } \\ \text { LC3 } & \text { microtubule-associated protein 1 light chain 3 } \\ \text { LIR } & \text { LC3-interacting region } \\ \text { NEDD8 } & \text { neural precursor cell expressed developmentally downregulated protein } 8 \\ \text { NMR } & \text { nuclear magnetic resonance } \\ \text { NOESY } & \text { nuclear Overhauser and exchange spectroscopy } \\ \text { R1, R2, R3 } & \text { UBA5 C-terminal regions R1, R2 and R3 } \\ \text { SD } & \text { standard deviation } \\ \text { SOFAST } & \text { band-selective optimized-flip-angle short-transient } \\ \text { SUMO } & \text { small ubiquitin related modifier } \\ \text { TOCSY } & \text { total correlation spectroscopy } \\ \text { TROSY } & \text { transverse relaxation optimized spectroscopy } \\ \text { UBA5 } & \text { UFM1-activating enzyme 5 } \\ \text { UBL } & \text { ubiquitin-like } \\ \text { UFBP1 } & \text { UFM1-binding protein 1 } \\ \end{array}$




$\begin{array}{ll}\text { UFC1 } & \text { UFM1-conjugating enzyme } 1 \\ \text { UFIM } & \text { UFM1-interacting motive } \\ \text { UFL1 } & \text { UFM1 ligase 1 } \\ \text { UFM1 } & \text { Ubiquitin fold modifier 1 } \\ \text { UfSP1/2 } & \text { UFM1-specific proteases } 1 \text { and 2 }\end{array}$

\section{References}

1. Komatsu, M.; Chiba, T.; Tatsumi, K.; Iemura, S.i.; Tanida, I.; Okazaki, N.; Ueno, T.; Kominami, E.; Natsume, T.; Tanaka, K. A novel protein-conjugating system for Ufm1, a ubiquitin-fold modifier. EMBO J. 2004, 23, 1977-1986. [CrossRef]

2. Sasakawa, H.; Sakata, E.; Yamaguchi, Y.; Komatsu, M.; Tatsumi, K.; Kominami, E.; Tanaka, K.; Kato, K. Solution structure and dynamics of Ufm1, a ubiquitin-fold modifier 1. Biochem. Biophys. Res. Commun. 2006, 343, 21-26. [CrossRef] [PubMed]

3. Banerjee, S.; Kumar, M.; Wiener, R. Decrypting UFMylation: How Proteins Are Modified with UFM1. Biomolecules 2020, 10, 1442. [CrossRef] [PubMed]

4. Daniel, J.; Liebau, E. The ufm1 cascade. Cells 2014, 3, 627-638. [CrossRef] [PubMed]

5. Ha, B.H.; Ahn, H.-C.; Kang, S.H.; Tanaka, K.; Chung, C.H.; Kim, E.E. Structural basis for Ufm1 processing by UfSP1. J. Biol. Chem. 2008, 283, 14893-14900. [CrossRef]

6. Ha, B.H.; Jeon, Y.J.; Shin, S.C.; Tatsumi, K.; Komatsu, M.; Tanaka, K.; Watson, C.M.; Wallis, G.; Chung, C.H.; Kim, E.E. Structure of ubiquitin-fold modifier 1-specific protease UfSP2. J. Biol. Chem. 2011, 286, 10248-10257. [CrossRef]

7. Kang, S.H.; Kim, G.R.; Seong, M.; Baek, S.H.; Seol, J.H.; Bang, O.S.; Ovaa, H.; Tatsumi, K.; Komatsu, M.; Tanaka, K. Two novel ubiquitin-fold modifier 1 (Ufm1)-specific proteases, UfSP1 and UfSP2. J. Biol. Chem. 2007, 282, 5256-5262. [CrossRef]

8. Bacik, J.-P.; Walker, J.R.; Ali, M.; Schimmer, A.D.; Dhe-Paganon, S. Crystal Structure of the Human Ubiquitin-activating Enzyme 5 (UBA5) Bound to ATP Mechanistic Insights into a Minimalistic E1 Enzyme. J. Biol. Chem. 2010, 285, 20273-20280. [CrossRef]

9. Gavin, J.M.; Hoar, K.; Xu, Q.; Ma, J.; Lin, Y.; Chen, J.; Chen, W.; Bruzzese, F.J.; Harrison, S.; Mallender, W.D. Mechanistic study of Uba5 enzyme and the Ufm1 conjugation pathway. J. Biol. Chem. 2014, 289, 22648-22658. [CrossRef] [PubMed]

10. Padala, P.; Oweis, W.; Mashahreh, B.; Soudah, N.; Cohen-Kfir, E.; Todd, E.A.; Berndsen, C.E.; Wiener, R. Novel insights into the interaction of UBA5 with UFM1 via a UFM1-interacting sequence. Sci. Rep. 2017, 7, 1-12. [CrossRef]

11. Mizushima, T.; Tatsumi, K.; Ozaki, Y.; Kawakami, T.; Suzuki, A.; Ogasahara, K.; Komatsu, M.; Kominami, E.; Tanaka, K.; Yamane, T. Crystal structure of Ufc1, the Ufm1-conjugating enzyme. Biochem. Biophys. Res. Commun. 2007, 362, 1079-1084. [CrossRef]

12. Tatsumi, K.; Sou, Y.-S.; Tada, N.; Nakamura, E.; Iemura, S.-I.; Natsume, T.; Kang, S.H.; Chung, C.H.; Kasahara, M.; Kominami, E. A novel type of E3 ligase for the Ufm1 conjugation system. J. Biol. Chem. 2010, 285, 5417-5427. [CrossRef]

13. Liang, J.R.; Lingeman, E.; Luong, T.; Ahmed, S.; Muhar, M.; Nguyen, T.; Olzmann, J.A.; Corn, J.E. A Genome-wide ER-phagy Screen Highlights Key Roles of Mitochondrial Metabolism and ER-Resident UFMylation. Cell 2020, 180, 1160-1177.e1120. [CrossRef]

14. Walczak, C.P.; Leto, D.E.; Zhang, L.; Riepe, C.; Muller, R.Y.; DaRosa, P.A.; Ingolia, N.T.; Elias, J.E.; Kopito, R.R. Ribosomal protein RPL26 is the principal target of UFMylation. Proc. Natl. Acad. Sci. USA 2019, 116, 1299-1308. [CrossRef]

15. Yang, R.; Wang, H.; Kang, B.; Chen, B.; Shi, Y.; Yang, S.; Sun, L.; Liu, Y.; Xiao, W.; Zhang, T. CDK5RAP3, a UFL1 substrate adaptor, is crucial for liver development. Development 2019, 146, dev169235. [CrossRef]

16. Yoo, H.M.; Kang, S.H.; Kim, J.Y.; Lee, J.E.; Seong, M.W.; Lee, S.W.; Ka, S.H.; Sou, Y.-S.; Komatsu, M.; Tanaka, K. Modification of ASC1 by UFM1 is crucial for ER $\alpha$ transactivation and breast cancer development. Mol. Cell 2014, 56, 261-274. [CrossRef] [PubMed]

17. Liu, J.; Guan, D.; Dong, M.; Yang, J.; Wei, H.; Liang, Q.; Song, L.; Xu, L.; Bai, J.; Liu, C. UFMylation maintains tumour suppressor p53 stability by antagonizing its ubiquitination. Nat. Cell Biol. 2020, 22, 1056-1063. [CrossRef] [PubMed]

18. Qin, B.; Yu, J.; Nowsheen, S.; Wang, M.; Tu, X.; Liu, T.; Li, H.; Wang, L.; Lou, Z. UFL1 promotes histone H4 ufmylation and ATM activation. Nat. Commun. 2019, 10, 1-13. [CrossRef] [PubMed]

19. Wang, Z.; Gong, Y.; Peng, B.; Shi, R.; Fan, D.; Zhao, H.; Zhu, M.; Zhang, H.; Lou, Z.; Zhou, J. MRE11 UFMylation promotes ATM activation. Nucleic Acids Res. 2019, 47, 4124-4135. [CrossRef] [PubMed]

20. Gak, I.A.; Vasiljevic, D.; Zerjatke, T.; Yu, L.; Brosch, M.; Roumeliotis, T.I.; Horenburg, C.; Klemm, N.; Bakos, G.; Herrmann, A. UFMylation regulates translational homeostasis and cell cycle progression. bioRxiv 2020. [CrossRef]

21. Cai, Y.; Pi, W.; Sivaprakasam, S.; Zhu, X.; Zhang, M.; Chen, J.; Makala, L.; Lu, C.; Wu, J.; Teng, Y. UFBP1, a key component of the Ufm1 conjugation system, is essential for ufmylation-mediated regulation of erythroid development. PLoS Genet. 2015, 11, e1005643. [CrossRef] [PubMed]

22. Hu, X.; Zhang, H.; Song, Y.; Zhuang, L.; Yang, Q.; Pan, M.; Chen, F. Ubiquitin fold modifier 1 activates NF-kB pathway by down-regulating LZAP expression in the macrophage of diabetic mouse model. Biosci. Rep. 2020, 40, BSR20191672. [CrossRef] [PubMed]

23. Lemaire, K.; Moura, R.F.; Granvik, M.; Igoillo-Esteve, M.; Hohmeier, H.E.; Hendrickx, N.; Newgard, C.B.; Waelkens, E.; Cnop, M.; Schuit, F. Ubiquitin fold modifier 1 (UFM1) and its target UFBP1 protect pancreatic beta cells from ER stress-induced apoptosis. PLoS ONE 2011, 6, e18517. [CrossRef] 
24. Roberts, A.M.; Miyamoto, D.K.; Huffman, T.R.; Bateman, L.A.; Ives, A.N.; Akopian, D.; Heslin, M.J.; Contreras, C.M.; Rape, M.; Skibola, C.F. Chemoproteomic screening of covalent ligands reveals UBA5 as a novel pancreatic cancer target. ACS Chem. Biol. 2017, 12, 899-904. [CrossRef] [PubMed]

25. Muona, M.; Ishimura, R.; Laari, A.; Ichimura, Y.; Linnankivi, T.; Keski-Filppula, R.; Herva, R.; Rantala, H.; Paetau, A.; Pöyhönen, M. Biallelic variants in UBA5 link dysfunctional UFM1 ubiquitin-like modifier pathway to severe infantile-onset encephalopathy. Am. J. Hum. Genet. 2016, 99, 683-694. [CrossRef]

26. Nahorski, M.S.; Maddirevula, S.; Ishimura, R.; Alsahli, S.; Brady, A.F.; Begemann, A.; Mizushima, T.; Guzmán-Vega, F.J.; Obata, M.; Ichimura, Y. Biallelic UFM1 and UFC1 mutations expand the essential role of ufmylation in brain development. Brain 2018, 141, 1934-1945. [CrossRef]

27. Tatsumi, K.; Yamamoto-Mukai, H.; Shimizu, R.; Waguri, S.; Sou, Y.-S.; Sakamoto, A.; Taya, C.; Shitara, H.; Hara, T.; Chung, C.H. The Ufm1-activating enzyme Uba5 is indispensable for erythroid differentiation in mice. Nat. Commun. 2011, 2, 1-7. [CrossRef]

28. Cappadocia, L.; Lima, C.D. Ubiquitin-like protein conjugation: Structures, chemistry, and mechanism. Chem. Rev. 2018, 118, 889-918. [CrossRef] [PubMed]

29. Oweis, W.; Padala, P.; Hassouna, F.; Cohen-Kfir, E.; Gibbs, D.R.; Todd, E.A.; Berndsen, C.E.; Wiener, R. Trans-binding mechanism of ubiquitin-like protein activation revealed by a UBA5-UFM1 complex. Cell Rep. 2016, 16, 3113-3120. [CrossRef]

30. Soudah, N.; Padala, P.; Hassouna, F.; Kumar, M.; Mashahreh, B.; Lebedev, A.A.; Isupov, M.N.; Cohen-Kfir, E.; Wiener, R. An N-terminal extension to Uba5 adenylation domain boosts Ufm1 activation: Isoform-specific differences in ubiquitin-like protein activation. J. Mol. Biol. 2019, 431, 463-478. [CrossRef] [PubMed]

31. Habisov, S.; Huber, J.; Ichimura, Y.; Akutsu, M.; Rogova, N.; Loehr, F.; McEwan, D.G.; Johansen, T.; Dikic, I.; Doetsch, V. Structural and functional analysis of a novel interaction motif within UFM1-activating enzyme 5 (UBA5) required for binding to ubiquitin-like proteins and ufmylation. J. Biol. Chem. 2016, 291, 9025-9041. [CrossRef]

32. Xie, S. Characterization, crystallization and preliminary X-ray crystallographic analysis of the human Uba5 C-terminus-Ufc1 complex. Acta Crystallogr. Sect. F Struct. Biol. Commun. 2014, 70, 1093-1097. [CrossRef]

33. Huber, J.; Obata, M.; Gruber, J.; Akutsu, M.; Löhr, F.; Rogova, N.; Güntert, P.; Dikic, I.; Kirkin, V.; Komatsu, M. An atypical LIR motif within UBA5 (ubiquitin like modifier activating enzyme 5) interacts with GABARAP proteins and mediates membrane localization of UBA5. Autophagy 2020, 16, 256-270. [CrossRef] [PubMed]

34. Colin, E.; Daniel, J.; Ziegler, A.; Wakim, J.; Scrivo, A.; Haack, T.B.; Khiati, S.; Denommé, A.-S.; Amati-Bonneau, P.; Charif, M. Biallelic variants in UBA5 reveal that disruption of the UFM1 cascade can result in early-onset encephalopathy. Am. J. Hum. Genet. 2016, 99, 695-703. [CrossRef]

35. Liu, G.; Forouhar, F.; Eletsky, A.; Atreya, H.S.; Aramini, J.M.; Xiao, R.; Huang, Y.J.; Abashidze, M.; Seetharaman, J.; Liu, J. NMR and X-ray structures of human E2-like ubiquitin-fold modifier conjugating enzyme 1 (UFC1) reveal structural and functional conservation in the metazoan UFM1-UBA5-UFC1 ubiquination pathway. J. Struct. Funct. Genom. 2009, 10, 127-136. [CrossRef] [PubMed]

36. Rogov, V.V.; Rozenknop, A.; Rogova, N.Y.; Löhr, F.; Tikole, S.; Jaravine, V.; Güntert, P.; Dikic, I.; Dötsch, V. A universal expression tag for structural and functional studies of proteins. ChemBioChem 2012, 13, 959-963. [CrossRef]

37. von Delbrück, M.; Kniss, A.; Rogov, V.V.; Pluska, L.; Bagola, K.; Löhr, F.; Güntert, P.; Sommer, T.; Dötsch, V. The CUE domain of Cue1 aligns growing ubiquitin chains with Ubc7 for rapid elongation. Mol. Cell 2016, 62, 918-928. [CrossRef] [PubMed]

38. Buetow, L.; Gabrielsen, M.; Anthony, N.G.; Dou, H.; Patel, A.; Aitkenhead, H.; Sibbet, G.J.; Smith, B.O.; Huang, D.T. Activation of a primed RING E3-E2-ubiquitin complex by non-covalent ubiquitin. Mol. Cell 2015, 58, 297-310. [CrossRef]

39. Dou, H.; Buetow, L.; Sibbet, G.J.; Cameron, K.; Huang, D.T. Essentiality of a non-RING element in priming donor ubiquitin for catalysis by a monomeric E3. Nat. Struct. Mol. Biol. 2013, 20, 982-986. [CrossRef]

40. Kumar, P.; Magala, P.; Geiger-Schuller, K.R.; Majumdar, A.; Tolman, J.R.; Wolberger, C. Role of a non-canonical surface of Rad6 in ubiquitin conjugating activity. Nucleic Acids Res. 2015, 43, 9039-9050. [CrossRef]

41. Eck, F.; Phuyal, S.; Smith, M.D.; Kaulich, M.; Wilkinson, S.; Farhan, H.; Behrends, C. ACSL3 is a novel GABARAPL2 interactor that links ufmylation and lipid droplet biogenesis. J. Cell Sci. 2020, 133, jcs243477. [CrossRef] [PubMed]

42. Farjon, J.; Boisbouvier, J.; Schanda, P.; Pardi, A.; Simorre, J.-P.; Brutscher, B. Longitudinal-relaxation-enhanced NMR experiments for the study of nucleic acids in solution. J. Am. Chem. Soc. 2009, 131, 8571-8577. [CrossRef] [PubMed]

43. Solyom, Z.; Schwarten, M.; Geist, L.; Konrat, R.; Willbold, D.; Brutscher, B. BEST-TROSY experiments for time-efficient sequential resonance assignment of large disordered proteins. J. Biomol. NMR 2013, 55, 311-321. [CrossRef]

44. Logan, T.M.; Olejniczak, E.T.; Xu, R.X.; Fesik, S.W. A general method for assigning NMR spectra of denatured proteins using 3D HC (CO) NH-TOCSY triple resonance experiments. J. Biomol. NMR 1993, 3, 225-231. [CrossRef] [PubMed]

45. Montelione, G.T.; Lyons, B.A.; Emerson, S.D.; Tashiro, M. An efficient triple resonance experiment using carbon-13 isotropic mixing for determining sequence-specific resonance assignments of isotopically-enriched proteins. J. Am. Chem. Soc. 1992, 114, 10974-10975. [CrossRef]

46. Löhr, F.; Hänsel, R.; Rogov, V.V.; Dötsch, V. Improved pulse sequences for sequence specific assignment of aromatic proton resonances in proteins. J. Biomol. NMR 2007, 37, 205-224. [CrossRef]

47. Brutscher, B.; Boisbouvier, J.; Pardi, A.; Marion, D.; Simorre, J.-P. Improved sensitivity and resolution in 1H- 13C NMR experiments of RNA. J. Am. Chem. Soc. 1998, 120, 11845-11851. [CrossRef] 
48. Pervushin, K.; Riek, R.; Wider, G.; Wüthrich, K. Transverse relaxation-optimized spectroscopy (TROSY) for NMR studies of aromatic spin systems in 13C-labeled proteins. J. Am. Chem. Soc. 1998, 120, 6394-6400. [CrossRef]

49. Zwahlen, C.; Legault, P.; Vincent, S.J.; Greenblatt, J.; Konrat, R.; Kay, L.E. Methods for measurement of intermolecular NOEs by multinuclear NMR spectroscopy: Application to a bacteriophage $\lambda$ N-peptide/boxB RNA complex. J. Am. Chem. Soc. 1997, 119, 6711-6721. [CrossRef]

50. Güntert, P. Automated structure determination from NMR spectra. Eur. Biophys. J. 2009, 38, 129-143. [CrossRef] [PubMed]

51. Berjanskii, M.V.; Neal, S.; Wishart, D.S. PREDITOR: A web server for predicting protein torsion angle restraints. Nucleic Acids Res. 2006, 34, W63-W69. [CrossRef] [PubMed]

52. Koradi, R.; Billeter, M.; Güntert, P. Point-centered domain decomposition for parallel molecular dynamics simulation. Comput. Phys. Commun. 2000, 124, 139-147. [CrossRef] 